Submitted, accepted and published by:

Fuel Processing Technology 178 (2018) 236-250

\title{
Mn-based oxygen carriers prepared by impregnation for Chemical Looping Combustion with diverse fuels
}

\author{
T.R. Costa ${ }^{a, b}$, P. Gayán ${ }^{a}$, A. Abad ${ }^{a}{ }^{,}$, F.García-Labiano ${ }^{a}$, L.F. de Diego ${ }^{a}$, \\ D.M.A. Melo ${ }^{b}$, J. Adánez $^{\mathrm{a}}$ \\ a Instituto de Carboquímica (ICB-CSIC), Miguel Luesma Castan 4, 50018 Zaragoza, Spain \\ ${ }^{\mathrm{b}}$ Chemical Institute (IQ-CCET), Federal University of Rio Grande do Norte, Natal, RN, Brasil \\ Corresponding author*: A. Abad; email: abad@icb.csic.es
}

\begin{abstract}
Chemical Looping Combustion (CLC) is considered one of the low cost alternatives for $\mathrm{CO}_{2}$ capture for fossil fuels combustion and to reach negative emissions through biomass CLC. The cornerstone of the CLC process is the oxygen carrier performance that represents the main additional cost with respect to the conventional combustion. Manganese-based oxygen carriers are subjected to a growing interest because they are low cost, not toxic and environmentally friendly. In this work five impregnated oxygen carriers, with manganese oxide $\mathrm{Mn}_{3} \mathrm{O}_{4}$ or $\mathrm{Mg}_{6} \mathrm{MnO}_{8}$ as their active phase and three commercial supports based on zirconia and synthetic calcium aluminate, were prepared. Their behaviour for CLC was examined by TGA, batch fluidized bed reactor, TPR, SEMEDX and XRD. After a preliminary screening two carriers (Mn-ZrM and Mn-ZrSG) were subjected to multiple redox cycles by TGA and batch fluidized bed reactor. Both showed high solids conversion by TGA under the tested conditions, appropriated resistance to fracture, rate indexes relatively high, although $\mathrm{Mn}$-ZrM showed agglomeration and deactivation during batch fluidized bed tests.
\end{abstract}

Reactivity in batch fluidized bed reactor of the Mn-ZrSG oxygen carrier with methane increases with temperature although suffered from significant deactivation. This was different to the results found during multiple redox cycles by TGA. There was not a clear reason for this decrease in the 
reactivity that likely could be due to the uncomplete oxidation in the batch fluidized bed reactor, although further investigations are needed. On the other hand, it presented high and constant reactivity with $\mathrm{CO}$ and $\mathrm{H}_{2}$ in all the range of temperatures tested, being suitable for iG-CLC processes of coal or biomass and syngas combustion. Agglomeration problems were not found and the attrition losses were small. Calculated lifetime was around 11000 hours, much higher than any other Mn-based material developed or tested for CLC.

Keywords: $\mathrm{CO}_{2}$ capture; Chemical Looping Combustion; Oxygen Carrier; Manganese oxide

\section{Introduction}

Chemical Looping Combustion (CLC) is considered as a low cost process for $\mathrm{CO}_{2}$ capture during combustion of gaseous and solid fuels due to its inherent $\mathrm{CO}_{2}$ separation and its low energy penalty. Chemical Looping Combustion process is based on the transfer of the oxygen from the air to the fuel through a solid oxygen carrier, avoiding the direct contact between the fuel and the air. In CLC, as shown in Fig. 1, fuel and air are never mixed and this kind of combustion can be classified as an unmixed combustion [1]. In the first step (reaction 1), the fuel is oxidized to $\mathrm{CO}_{2}$ and $\mathrm{H}_{2} \mathrm{O}$ by a metal oxide $\left(\mathrm{Me}_{x} \mathrm{O}_{y}\right)$ that is reduced to $\mathrm{Me}_{x} \mathrm{O}_{y-1}$. The water generated in the process can be easily separated by condensation, thus obtaining a highly concentrated stream of $\mathrm{CO}_{2}$, ready for transportation and storage [2]. The reduced metal oxide is further oxidized with air (reaction 2) in a second step and the regenerated material is ready for a new cycle.

$$
\begin{aligned}
& (2 n+m) \mathrm{Me}_{x} \mathrm{O}_{y}+\mathrm{C}_{n} \mathrm{H}_{2 m} \longrightarrow(2 n+m) \mathrm{Me}_{x} \mathrm{O}_{y-1}+\mathrm{mH}_{2} \mathrm{O}+\mathrm{nCO}_{2} \\
& 2 \mathrm{Me}_{x} \mathrm{O}_{\mathrm{y}-1}+\mathrm{O}_{2} \longrightarrow 2 \mathrm{Me}_{x} \mathrm{O}_{y}
\end{aligned}
$$

CLC concept has been proposed to be carried out in different types or reactors and configurations. The more common configuration of the CLC system corresponds to two interconnected fluidized 
bed reactors, which are designated as: air reactor (AR) and fuel reactor (FR), with particles of metal oxide (oxygen carrier) circulating between the two reactors [2].

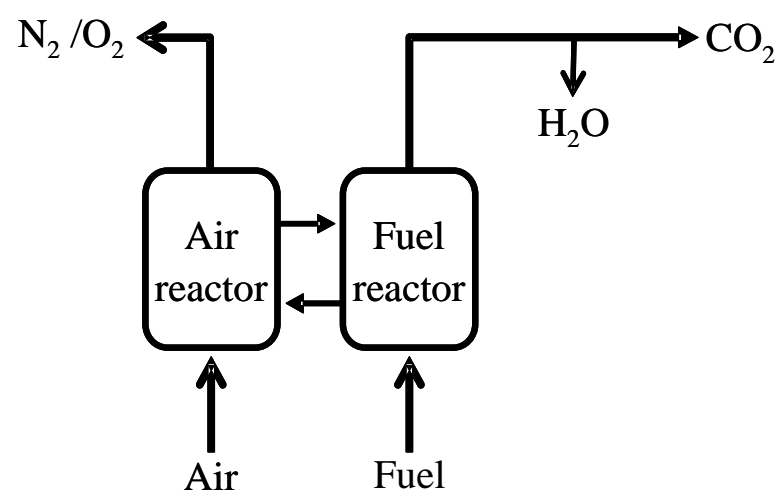

Fig. 1. Simplified diagram of the CLC system.

An overview of the CLC process applied to the combustion of gaseous and solid fuels can be found in a number of review publications [3-7]. In the last few years, significant efforts have been made in the area of oxygen carrier development. $[3,4,6]$. Most of the oxygen carriers proposed in the literature as suitable for gas combustion $\left(\mathrm{CH}_{4}\right.$, natural gas, $\left.\mathrm{CO}+\mathrm{H}_{2}\right)$ are synthetic materials using as active metal oxides ( $\mathrm{CuO}, \mathrm{Fe}_{2} \mathrm{O}_{3}, \mathrm{NiO}$ and $\mathrm{Mn}$ oxides) and some mixed oxides with perovskite structure, containing Mn. Moreover, there are some studies showing the suitability of the use of minerals as iron and manganese ores, ilmenite or waste materials coming from steel industry and alumina production, although their performance is usually lower [6].

The cornerstone of CLC process is the performance of the oxygen carrier. This material must display a number of different characteristics in order to be suitable for CLC. Oxygen carriers needs to have sufficient oxygen transport capacity $\left(R_{O C}\right)$, with high reactivity both for reduction and oxidation reactions and this must be maintained for a large number of redox cycles. Oxygen carriers need to have favourable thermodynamics regarding fuel conversion to $\mathrm{CO}_{2}$ and $\mathrm{H}_{2} \mathrm{O}$. Moreover, negligible carbon deposition during reduction is needed to avoid C shortcutting to the air reactor, which reduces overall $\mathrm{CO}_{2}$ capture efficiency. Good fluidization properties and no 
agglomeration in the reactors are fundamental for the smooth operation of interconnected fluidized bed reactors. Environmental and health issues must be considered to ensure the process meets future high standards of environmental performance.

Resistance to the attrition is a key point in order to reduce losses of elutriated fines and to reduce the oxygen carrier makeup costs when fluidized bed reactors are used. Thus, the main additional cost for CLC corresponds to the cost of the oxygen carrier replacement. The cost of the makeup stream of solids to replace the loss of fines will depend on: the lifetime of the oxygen carrier particles, the inventory in the CLC system and the cost of the oxygen carrier, which is mainly affected by the oxygen carrier reactivity, metal used and its content in the carrier. The oxygen carrier inventory depends mainly on the oxygen carrier reactivity; the redox pair used; the flow characteristics of gas and solids in the reactors, the solid circulation between reactors and the bed pressure drop [6]. Rate indexes can be used to extrapolate inventories, although give inaccurate values which only can be considered for initial estimations. However rate indexes can be used to compare the reactivity of different oxygen carriers. The rate index corresponds to the $\%$ of metal oxide mass that reacts per minute [8] and can be determined at a gas concentration corresponding to the mean value in the reactor.

Rate index $(\% / \mathrm{min})=60 \cdot 100(\mathrm{~d} \omega / \mathrm{d} t)$

where $\omega$ is calculated by $\omega=m / m_{o x}, m_{o x}$ being the mass of the sample in the most oxidized state and $m$ the mass of the sample at any reacting time $t$.

$\mathrm{Ni}$ oxygen carriers suffer from environmental and health risks and $\mathrm{Cu}$ is a relatively expensive material and temperatures lower than $900{ }^{\circ} \mathrm{C}$ are recommended due to the low Tammann temperature of metallic copper, as well as in order to extend the lifetime of most promising materials impregnated on alumina [6]. On the contrary iron is considered a low cost and non-toxic material, although reactivity of Fe-based oxygen carriers is limited. Mn-based oxygen carriers are 
also cheap materials, non-toxic and environmentally friendly. Moreover, they have high melting point and oxygen transport capacity when compared with Fe-based oxygen carriers.

Mn-based oxygen carriers accomplish most basic requirements to be used as oxygen carrier [6] and when compared with iron carriers, it developed a similar or a superior activity, besides being inexpensive and non-toxic [9]. Another benefit is that some fuels have sulphur compounds in their composition, that react with the oxygen carrier forming sulphides in the CLC process, for example, materials that have in their base $\mathrm{Ni}$ and Co. However, manganese-based carriers, are thermodynamically stable in a CLC environment with fuels that have sulphur in their composition $[6,10]$

Several oxidation states may be involved in redox reactions of manganese. $\mathrm{MnO}_{2}$, compound decompose in air at $500^{\circ} \mathrm{C}$, while the $\mathrm{Mn}_{2} \mathrm{O}_{3}$ is thermodynamically stable in air at temperatures below $900^{\circ} \mathrm{C}[6,11,12]$. Thus, the redox transformation among $\mathrm{Mn}_{3} \mathrm{O}_{4}$ to $\mathrm{MnO}$ is considered the most feasible for $\mathrm{CLC}[6,13]$. The $\mathrm{Mn}_{3} \mathrm{O}_{4} / \mathrm{MnO}$ system is capable to convert completely $\mathrm{CH}_{4}$ to $\mathrm{CO}_{2}$ and $\mathrm{H}_{2} \mathrm{O}[10]$. Despite the promising properties of manganese to be used as oxygen carrier, few materials based on $\mathrm{Mn}$ were tested in CLC, especially when compared to nickel, copper and iron. Synthetic manganese-based oxygen carriers reported in the literature are combinations of active phase and support, where in most of them solid state reactions between $\mathrm{Mn}$ and the support occurred, decreasing the reactivity of these materials. Manganese-based carriers deposited/impregnated with alumina or silica, usually presented aluminates and silicates formation, respectively. The formation of these mixed oxides, reduces the reactivity of the material, presenting low fuel conversion $[8,11,14-16]$. Titanium oxide $\left(\mathrm{TiO}_{2}\right)$ was also used as a support for $\mathrm{Mn}_{3} \mathrm{O}_{4}$, showing low reactivity due to the formation of titanates during the sintering process of the material [15]. Some comprehensive screening studies [8,15-21] selected Mn-based oxygen carriers supported on $\mathrm{ZrO}_{2}$ or $\mathrm{ZrO}_{2}$ stabilized with $\mathrm{MgO}$ as suitable for $\mathrm{CLC}$ process.

One oxygen carrier selected in [8] containing $40 \% \mathrm{Mn}_{3} \mathrm{O}_{4}$ and $60 \% \mathrm{MgO}$ stabilized $\mathrm{ZrO}_{2}$ was tested in a $300 \mathrm{~W}$ continuous CLC unit [9] at temperatures from 850 to $950{ }^{\circ} \mathrm{C}$ burning syngas and 
natural gas during $70 \mathrm{~h}$ with encouraging results. This carrier was best suited for syngas combustion reaching combustion efficiencies higher than $99 \%$. For natural gas combustion efficiencies of $87.8 \%$ at $850{ }^{\circ} \mathrm{C}$ and $99 \%$ at $959{ }^{\circ} \mathrm{C}$ were found. Although crushing strength was $1.1 \mathrm{~N}$, the attrition losses found were low, $0.038 \% / \mathrm{h}$, with a calculated lifetime of $2630 \mathrm{~h}$. The reaction kinetics was determined for this carrier and reaction orders of 1 for reduction with $\mathrm{CH}_{4}$ and 0.65 with $\mathrm{O}_{2}$ were found. The activation energies were $119 \mathrm{~kJ} / \mathrm{mol}$ and $19 \mathrm{~kJ} / \mathrm{mol}$ for the reduction and the oxidation respectively [12].

Manganese ores have a great potential to be considered as oxygen carriers in CLC processes using solid fuels or syngas and its reactivity has been measured in different investigations. Depending of the origin of the ore the reactivity and the attrition behaviour show significant differences [2228]. Mn-Fe mixed oxides depending on the composition and calcination conditions are capable of generate gaseous oxygen and also to use lattice oxygen for $\mathrm{CH}_{4}, \mathrm{CO}$ and $\mathrm{H}_{2}$ combustion [28-32]. Some investigations on Mn-Fe mixed oxides have been also carried out showing the capability of this kind of materials to burn fuels in CLC units [32-34]. Rydén et al. [33,34] used Fe-Mn and MnFe-Ti [34] materials in a $300 \mathrm{~W}_{\text {th }}$ unit to burn methane. Good conversion of methane was found although the lifetime of the particles was extremely short. $\left(\mathrm{Mn}_{0.77} \mathrm{Fe}\right)_{2} \mathrm{O}_{3}$ was investigated in a 500 $\mathrm{W}_{\text {th }}$ unit burning gaseous fuels and also different solid fuels [32] showing good reactivity for $\mathrm{CO}$, $\mathrm{H}_{2}$ and solid fuels with high lifetimes (6120 h).

The aim of this work is the development of impregnated Mn based oxygen carriers using different supports and their characterization for Chemical Looping Combustion. Mn-based oxygen carriers prepared by incipient wetness impregnation on $\mathrm{CaAl}_{2} \mathrm{O}_{4}$ and $\mathrm{ZrO}_{2}$ of different sources were developed and examined for CLC by TGA and batch fluidized bed reactor testing. In order to select promising materials for CLC in continuous units, oxygen carriers were evaluated regarding the mechanical properties, reactivity with fuel gases and $\mathrm{O}_{2}$ in order to select the more promising materials. Selected materials were further tested in a batch fluidized bed reactor during multiple redox cycles with fuel gases to know the fluidization behaviour, agglomeration behaviour and the 
attrition resistance. Fresh and after being used carriers were also tested by several characterization techniques to analyse the evolution of their chemical and structural properties during CLC redox cycles.

\section{Experimental}

\subsection{Oxygen Carrier preparation}

Five oxygen carriers were prepared by incipient wetness impregnation using as supports calcium aluminate or zirconia, with manganese oxides as the active phase. The active metal oxide was obtained from manganese nitrate solutions (5 or $7 \mathrm{M}$ of $\mathrm{Mn}\left(\mathrm{NH}_{3}\right)_{2} .4 \mathrm{H}_{2} \mathrm{O}$, Merck) impregnated on the supports. Three zirconia-based supports were used: MELChemicals, YanYu Industrial and Saint Gobain (Zirpro). The $\mathrm{CaAl}_{2} \mathrm{O}_{4}$ support was prepared by a mechanical mixing followed by pelletizing under pressure and calcination [35]. Table 1 presents the supports used, the adopted nomenclature, the methodology of preparation used, the metal oxide fraction and the oxygen transport capacity of the developed materials [36]. The oxygen transport capacity of the materials $\left(R_{O C}\right)$ was determined using the temperature programed reduction results obtained in the $\mathrm{Cl}$ Electronics thermobalance used in the reactivity experiments.

Table 1. Characteristics of the developed oxygen carriers.

\begin{tabular}{lllccc}
\hline Support & \multicolumn{1}{c}{ Nomenclature } & Prep. method & Steps & $\mathrm{Mn}_{3} \mathrm{O}_{4}(\%)$ & $R_{O C}$ \\
\hline $\mathrm{CaAl}_{2} \mathrm{O}_{4}$ (Syntetic) & $\mathrm{Mn}-\mathrm{CaAl}$ & $\mathrm{IHI}$ & 2 & 15.9 & 1.1 \\
$\mathrm{ZrO}_{2}$ (Yanyu) & $\mathrm{Mn-ZrY}$ & $\mathrm{IHI}$ & 2 & 18.8 & 1.3 \\
$\mathrm{ZrO}_{2}$ (Saint Gobain) & $\mathrm{Mn-ZrSG}$ & $\mathrm{IHI}$ & 2 & 16.3 & 1.1 \\
$\mathrm{ZrO}_{2}$ (MELChemicals) & $\mathrm{Mn}-\mathrm{ZrMH}$ & $\mathrm{IHI}$ & 1 & 21.4 & 2.7 \\
$\mathrm{ZrO}_{2}$ (MELChemicals) & $\mathrm{Mn}-\mathrm{ZrM}$ & $\mathrm{II}$ & 1 & 15.3 & 2.0 \\
\hline
\end{tabular}

Example of nomenclature of the oxygen-carrier: Mn-ZrSG, the Mn matches the active phase (manganese oxide); the $\mathrm{Zr}$ is the inert support ( $\mathrm{ZrO}_{2}$-based), SG the support source (in this case Saint Gobain). In preparation method " $\mathrm{H}$ " indicates that the oxygen carrier was prepared by incipient hot impregnation. 


\subsection{Oxygen Carrier Characterization}

The oxygen carriers were characterized by X-ray diffraction (XRD), in a Bruker D8 Advance Series 2 equipment, using CuKa as the radiation source, with a voltage of $40 \mathrm{KV}$, a current of $40 \mathrm{~mA}$, a graphite diffracted beam monochromator, with a step of 0.05 degrees. The sample holder used had a zero background, manufactured in Silicon Crystal and is indicated for small amounts of sample. The sample holder was kept in horizontal position with rotation, to minimize the effect of preferential orientation of the crystals. Data were collected in the range of $2 \theta$ (two theta) from 3 to 80 degrees. The identification of crystalline structures and phases presented were obtained by reference sheets of the JCPDS (Joint Committee on Powder Diffraction Standards) contained in the database of the ICDD (International Center for Diffraction Date, 2003 version).

The resistance to fracture for both supports and oxygen carriers were measured using a Shimpo FGN-5X equipment. The crushing strength is the average of 20 measurements performed for each material. Temperature programmed reduction (TPR) experiments were obtained with an AUTOCHEM II equipment from Micromeritics. This analysis used about $180 \mathrm{mg}$ of dried sample. The sample was heated to a temperature up to $1000^{\circ} \mathrm{C}$, with a heating rate of $7{ }^{\circ} \mathrm{C} / \mathrm{min}$, using $10 \% \mathrm{H}_{2}-90 \% A r$ as reducer gas, with a flow rate of $0.02 \mathrm{~L} / \mathrm{min}$. The reduction temperatures and $\mathrm{H}_{2}$ consumption data were obtained by a thermal conductivity detector (TCD). The morphology of the oxygen carriers was evaluated before and after the reactor experiments, by Scanning Electron Microscopy (SEM) and Energy Dispersive Spectroscopy (EDS) using an equipment of Shimadzu, model SSX 550 SuperScan.

\subsection{Oxygen Carrier reactivity testing}

\subsubsection{Thermogravimetric Analyser}

The reactivity of oxygen carriers was measured using a thermogravimetric analyser, $\mathrm{Cl}$ Eletronics. The setup has a system to receive the data, and a gas supplying system with mass flow controllers to prepare the reacting gas mixture. The methodology used the variations of mass in the oxygen 
carrier, when it was subjected to temperatures and different reacting gases during redox cycles.

The conversion of the samples was obtained using Eqs. (4) and (5) 1 and 2 [12].

Reduction: $\quad X_{r e d}=\frac{m_{o x}-m}{m_{o x}-m_{r e d}}$

Oxidation: $\quad X_{o x}=1-\frac{m_{o x}-m}{m_{o x}-m_{r e d}}$

where $X_{\text {red }}$ and $X_{o x}$ are the reduction and oxidation conversions, respectively; $m_{o x}$ is the mass of the sample in the most oxidized state under the tested conditions; $m_{\text {red }}$ is the mass of the sample in the most reduced state; and $m$ the mass of the sample. For data evaluation it was considered that the mass of $100 \%$ would correspond to the sample in its higher oxidation state analysed.

A sample of $50 \mathrm{mg}$ was heated up by synthetic air until the reacting temperature ( 850 or $950{ }^{\circ} \mathrm{C}$ ). When the desired temperature was reached and the stability of the system was checked, the experiments began and the oxygen carrier was subjected to several reduction/oxidation cycles. To prevent the mixture of the reduction and oxidation gases, nitrogen was introduced between each reduction and oxidation stage.

During the experiments, the gas flow was maintained at $25 \mathrm{NL} / \mathrm{h}$, seeking to reduce the oscillations occurred when there was a change of gases and to minimize the resistance to gas film diffusion. A gas composition of $15 \%$ of fuel $\left(\mathrm{H}_{2}\right.$ or $\left.\mathrm{CH}_{4}\right)$ and $20 \%$ of water vapour was used during reduction, and synthetic air during oxidation. The steam was used to prevent the deposition of carbon when carbon-containing gases were used. This experiment was able to determine, together reactivity several other parameters, which ensure that the carrier is feasible for CLC, such as the effective amount of metal oxide, the rate index and the oxygen transport capacity of the oxygen carrier.

\subsubsection{Fluidized bed facility}

A batch fluidized bed reactor, was used since it resemble the conditions of a CLC process, and it allows to evaluate the distribution of the products formed in the reduction and oxidation steps; fluidization/agglomeration problems; to determine the attrition rates; and to analyse the carbon 
deposition. Fig. 2 shows a diagram of the batch fluidized bed setup used. The setup consists of a gas supply system, a fluidized bed batch reactor, two solid recovery filters from the reactor and a system that analyses the outlet gases of the reactor [37]. The gas supply and steam system were composed by different mass flow controllers that are connected to the bottom of the reactor. Always between a period of reduction or oxidation, pure $\mathrm{N}_{2}$ was flowed to avoid contact between the reducer and oxidant gases. This system allowed the use of different fuel gas mixtures, as well as different oxidizing gases.

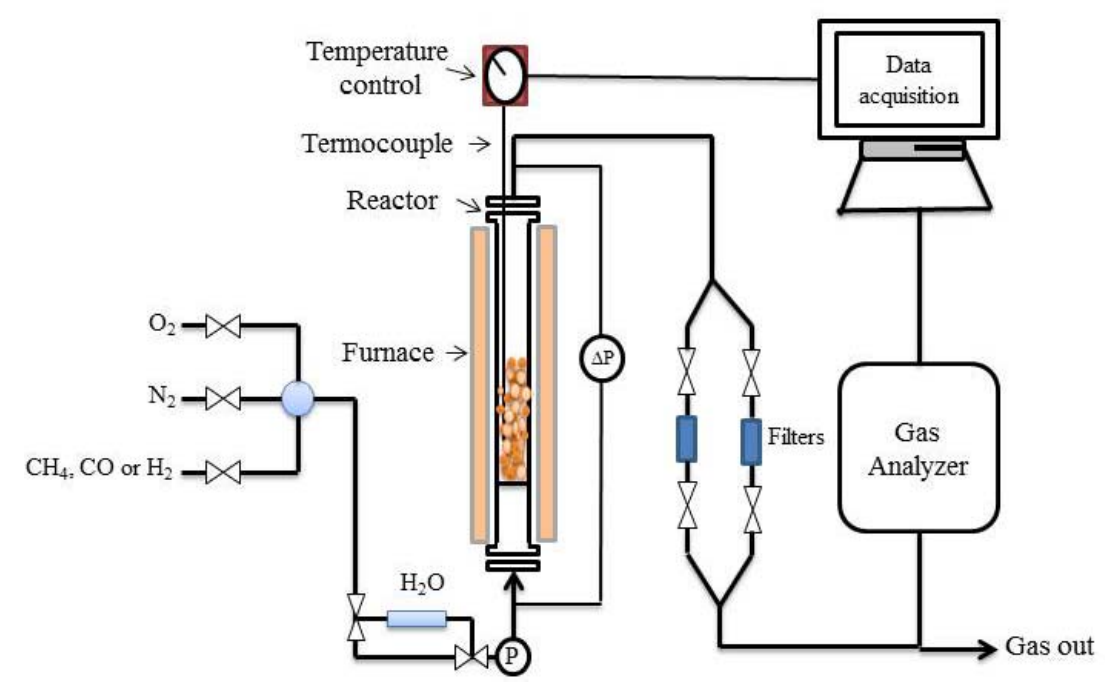

Fig. 2: Schematic diagram of the discontinuous fluidized bed reactor.

For the experiments, around 300 grams of oxygen carrier were used, with a particle size from 100 to $300 \mu \mathrm{m}$. The superficial gas velocity was fixed at least three times the minimum fluidization velocity. The gas velocity was chosen to have a good fluidization without particle entrainment. Table 2 presents the composition of the reactive gases and temperatures used during the experiments performed in the reactor. Reduction reaction times were selected to match the stoichiometric fuel gas consumption. For the oxidation the time needed for complete oxidation was used. 
Table 2. Experimental conditions used during batch fluidized bed reactor experiments.

\begin{tabular}{ccc}
\hline Temperature $\left({ }^{\circ} \mathrm{C}\right)$ & Reduction Stage & Oxidation Stage \\
\hline & $25 \% \mathrm{CH}_{4}+10 \% \mathrm{H}_{2} \mathrm{O}+65 \% \mathrm{~N}_{2}$ & \\
850,900 and $950{ }^{\circ} \mathrm{C}$ & $50 \% \mathrm{H}_{2}+20 \% \mathrm{H}_{2} \mathrm{O}+30 \% \mathrm{~N}_{2}$ & $5 \% \mathrm{O}_{2}+95 \% \mathrm{~N}_{2}$ \\
& $50 \% \mathrm{CO}+20 \% \mathrm{CO}_{2}+30 \% \mathrm{~N}_{2}$ & \\
\hline
\end{tabular}

The composition of the gases at the outlet of the fluidized bed batch reactor was determined using different continuous gas analysers. The concentrations of $\mathrm{CO}, \mathrm{CO}_{2}$ and $\mathrm{CH}_{4}$ was determined through a non-dispersive infrared analyser (NDIR) from Maihak S710/UNOR. The $\mathrm{H}_{2}$ concentration was determined by a thermal conductivity detector (TCD) from MAIHAK S710 model THERMOR, and the concentration of $\mathrm{O}_{2}$ with a paramagnetic analyser from Siemens OXYMAT 5E model. The concentrations of the gases are recorded continuously after the reactor outlet. From these data the solid conversion as a function of time was calculated. Time corrections were made, due to the delay to reach the gas analysers. The Eqs. (6) and (7) were determined based on the mass balance and were used to calculate the solid conversion in the reduction and oxidation steps, respectively [37].

Reduction stage:

$$
X_{\text {red }}=\frac{1}{n_{0}} \int_{t_{0}}^{t_{\text {red }}}\left\{F_{\text {out }}\left(2 y_{\mathrm{CO}_{2}, \text { out }}+y_{\mathrm{CO}, \text { out }}+y_{\mathrm{H}_{2} \mathrm{O}, \text { out }}\right)-F_{\text {in }}\left(2 y_{\mathrm{CO}_{2} \text { in }}+y_{\mathrm{CO}, \text { in }}-y_{\mathrm{H}_{2} \mathrm{O}, \text { in }}\right)\right\} \mathrm{d} t
$$

Oxidation stage:

$$
X_{\text {ox }}=\frac{2}{n_{0}} \int_{t_{0}}^{t_{\text {ox }}} F_{\text {out }}\left(\frac{F_{\text {in }}}{F_{\text {out }}} y_{\mathrm{O}_{2}, \text { in }}-y_{\mathrm{O}_{2}, \text { out }}-\frac{1}{2} y_{C O, \text { out }}-y_{\mathrm{CO}_{2}, \text { out }}\right) \mathrm{d} t
$$


where $X_{\text {red }}$ and $X_{o x}$ is the conversion of the oxygen carrier during the reduction and oxidation stages, respectively; $F_{\text {in }}$ and $F_{\text {out }}$ are the molar gas flow at the inlet and outlet of the reactor, respectively; $y_{i, i n}$ is the molar fraction of the $i$ gas at the inlet of the reactor; $y_{i, \text { out }}$ is the molar fraction of the $i$ gas in the reactor outlet; $n_{0}$ is the number of moles of oxygen that the oxygen carrier can provide in its most oxidized state; and $t$ is the time of the reaction.

To determine the attrition rate, the solids recovered in the filters were weighted and subsequently its particle size distribution was determined, whereas the particles with a size under than $40 \mu \mathrm{m}$ were considered as generated by attrition. The attrition rate was calculated through Eq. (8).

$$
n_{\text {attrition }}=\frac{\frac{m_{\text {elut }}}{m_{O C}}}{t} * 100 * 3600[\% / h]
$$

where $n_{\text {attrition }}$ is the attrition rate $(\% / h) ; m_{\text {elut }}$ is the mass of oxygen carrier with a particle size smaller than $40 \mu \mathrm{m} ; m_{O C}$ is the total mass of the oxygen carrier in the bed, and $t$ the time of operation in which the sample was collected from filters. From the attrition rate, it is also possible to calculate the average lifetime of the oxygen carriers.

\section{Results}

\subsection{Oxygen Carrier characterization}

X-ray diffraction (XRD) of the supporting porous particles was done to know the main constituents of these materials. The synthetic $\mathrm{CaAl}_{2} \mathrm{O}_{4}$ support showed $\mathrm{CaAl}_{2} \mathrm{O}_{4}$ and $\mathrm{CaAl}_{4} \mathrm{O}_{7}$ phases in the monoclinic structure, evidencing the efficiency of the methodology used in the synthesis of the material [35]. The supports from YanYu Industrial and Saint Gobain were composed by zirconia $\left(\mathrm{ZrO}_{2}\right)$ and were used without any prior treatment to obtain the manganese-based oxygen carrier. In both diffractograms the baddeleyite phase was identified, which has the chemical formula $\mathrm{ZrO}_{2}$ and a monoclinic crystalline structure. The support from MELChemicals (ZrM) was composed by hydrotalcite and zirconia. This support $\mathrm{ZrM}$ presented peaks for $\mathrm{MgO}$ and $\mathrm{ZrO}_{2}$, both with cubic 
structure, although it was not possible to identify any structure for the aluminum present in hydrotalcite.

$\mathrm{Mn}$-CaAl, $\mathrm{Mn}$-ZrY and $\mathrm{Mn}$-ZrSG oxygen carriers only have $\mathrm{Mn}_{3} \mathrm{O}_{4}$ as their active phase, with the name of hausmanite with tetragonal structure. Equally, the XRD results not showed crystalline structures that could be assigned to interactions of active phase with the support or a change in their structures, indicating that neither $\mathrm{CaAl}_{2} \mathrm{O}_{4}$ nor $\mathrm{ZrO}_{2}$ react with manganese oxide in the synthesis conditions used [35]. In the oxygen carriers prepared with MELChemicals (ZrM) (Mn$\mathrm{ZrMH}$ and $\mathrm{Mn}-\mathrm{ZrM}$ ) the same phases were identified: $\mathrm{MgAl}_{2} \mathrm{O}_{4}, \mathrm{MgO}, \mathrm{ZrO}_{2}, \mathrm{Mg}_{6} \mathrm{MnO}_{8}$ and $\mathrm{Mn}_{3} \mathrm{O}_{4}$. The formation of the $\mathrm{MgAl}_{2} \mathrm{O}_{4}$ spinel occurred due to reaction between aluminium and magnesium oxides, both from the hydrotalcite when subjected to high temperatures. The active phases identified in these oxygen carriers were $\mathrm{Mn}_{3} \mathrm{O}_{4}$ and $\mathrm{Mg}_{6} \mathrm{MnO}_{8}$, with the manganese oxidation states of $+8 / 3$ and +4 , respectively. The $\mathrm{Mg}_{6} \mathrm{MnO}_{8}$ material has an oxidation state similar of $\mathrm{MnO}_{2}$, which has high oxygen transfer capacity. It is believed that both the excess magnesium oxide in support as well as the calcination conditions promoted the formation of a mixed oxide, composed by magnesium and manganese $\left(\mathrm{Mg}_{6} \mathrm{MnO}_{8}\right)[38,39]$.

Table 3 shows the references letters, chemical formulas, crystalline structures, crushing strength and reduction and oxidation rate indexes found for the prepared oxygen carriers. Although it was not established a relationship between the mechanical resistance, through the crushing strength, and the half-life of an oxygen carrier, it was accepted that particles with the crushing strength lower than $1 \mathrm{~N}$ were overly fragile to be used in CLC systems with continuous circulation of solids [8]. Prepared oxygen carriers, presented a crushing strength higher than $1 \mathrm{~N}$, except the material Mn-CaAl. With the impregnation of the support ZrY, a significant increase in the crushing strength from 0.7 to 7.3 was observed. 
Table 3. Properties of supports and developed oxygen carriers.

\begin{tabular}{|c|c|c|c|c|c|c|}
\hline \multirow[t]{2}{*}{ Sample } & \multirow{2}{*}{$\begin{array}{c}\text { References of } \\
\text { JCPDS }\end{array}$} & \multirow{2}{*}{$\begin{array}{l}\text { Chemical } \\
\text { formulas }\end{array}$} & \multirow[t]{2}{*}{ Structures } & \multirow{2}{*}{$\begin{array}{c}\text { Crushing } \\
\text { Strength (N) }\end{array}$} & \multicolumn{2}{|c|}{ Rate Index (\%/min) } \\
\hline & & & & & Reduction & Oxidation \\
\hline \multirow[t]{2}{*}{ CaAl } & 01-070-0134 & $\mathrm{CaAl}_{2} \mathrm{O}_{4}$ & Monoclinic & 0.7 & & \\
\hline & 01-074-1467 & $\mathrm{CaAl}_{4} \mathrm{O}_{7}$ & Monoclinic & & & \\
\hline Mn-CaAl & $01-080-0382$ & $\mathrm{Mn}_{3} \mathrm{O}_{4}$ & Tetragonal & 0.8 & 4.1 & 9.1 \\
\hline $\mathrm{ZrY}$ & 01-074-1200 & $\mathrm{ZrO}_{2}$ & Monoclinic & 0.8 & & \\
\hline $\mathrm{Mn}-\mathrm{ZrY}$ & $01-080-0382$ & $\mathrm{Mn}_{3} \mathrm{O}_{2}$ & Tetragonal & 7.3 & 3.0 & 2.1 \\
\hline ZrSG & 01-074-1200 & $\mathrm{ZrO}_{2}$ & Monoclinic & 1.1 & & \\
\hline $\mathrm{Mn}-\mathrm{ZrSG}$ & $01-080-0382$ & $\mathrm{Mn}_{3} \mathrm{O}_{4}$ & Tetragonal & 2.5 & 13.1 & 8.5 \\
\hline \multirow[t]{2}{*}{ ZrM } & 01-087-0653 & $\mathrm{MgO}$ & Cubic & 1.0 & & \\
\hline & 00-027-0997 & $\mathrm{ZrO}_{2}$ & Cubic & & & \\
\hline \multirow[t]{5}{*}{$\mathrm{Mn}-\mathrm{ZrM}$} & $00-011-0031$ & $\mathrm{Mg}_{6} \mathrm{MnO}_{8}$ & Cubic & 3.4 & 6.8 & 4.1 \\
\hline & 01-080-0382 & $\mathrm{Mn}_{3} \mathrm{O}_{4}$ & Tetragonal & & & \\
\hline & 01-088-1007 & $\mathrm{ZrO}_{2}$ & Tetragonal & & & \\
\hline & 00-030-0794 & $\mathrm{MgO}$ & Cubic & & & \\
\hline & 01-077-0437 & $\mathrm{MgAl}_{2} \mathrm{O}_{4}$ & Cubic & & & \\
\hline \multirow[t]{5}{*}{$\mathrm{Mn}-\mathrm{ZrMH}$} & $00-011-0031$ & $\mathrm{Mg}_{6} \mathrm{MnO}_{8}$ & Cubic & 4.6 & 5.9 & 5.7 \\
\hline & 01-080-0382 & $\mathrm{Mn}_{3} \mathrm{O}_{4}$ & Tetragonal & & & \\
\hline & 01-088-1007 & $\mathrm{ZrO}_{2}$ & Tetragonal & & & \\
\hline & 00-030-0794 & $\mathrm{MgO}$ & Cubic & & & \\
\hline & 01-077-0437 & $\mathrm{MgAl}_{2} \mathrm{O}_{4}$ & Cubic & & & \\
\hline
\end{tabular}

The results for temperature programmed reduction proved the formation of manganese oxides identified by XRD. The reduction of $\mathrm{Mn}_{3} \mathrm{O}_{4}$ to $\mathrm{MnO}$ was demonstrated by the reduction peaks in TPR ranging from $350-550{ }^{\circ} \mathrm{C}$, and the position of the peak depends on the size and morphology of the particles of $\mathrm{Mn}_{3} \mathrm{O}_{4}$; see Fig. 3a $[40,41]$. It is noticed that the Mn-ZrSG material has a greater 
trend to be reduced than other materials, since its reduction occurs in a lower temperature range. The reduction profile of the material Mn-ZrSG reveals there was not interaction between $\mathrm{Mn}_{3} \mathrm{O}_{4}$ and support. The material Mn-ZrY has a reduction peak that is intermediate when compared with the previous one, although it presents a region of difficult reduction at temperatures above 500 ${ }^{\circ} \mathrm{C}$. The carrier $\mathrm{Mn}-\mathrm{ZrY}$ presented one less intense reduction peak, possibly due to the formation of $\mathrm{Mn}_{3} \mathrm{O}_{4}$ particles with a reduction more difficult. This fact could be proven by the region with temperature of $515^{\circ} \mathrm{C}$ where the reduction occurs slowly. This difficulty to reduce the $\mathrm{Mn}$ - $\mathrm{ZrY}$ could affect the reduction rate of the material during the reactivity tests, reducing its effective use for oxygen transport. The material Mn-CaAl presented a maximum reduction around $500{ }^{\circ} \mathrm{C}$ and it was also possible to check a shoulder at $528{ }^{\circ} \mathrm{C}$, that can be attributed to the low intensity interactions among the particles of the $\mathrm{Mn}_{3} \mathrm{O}_{4}$ and the support.
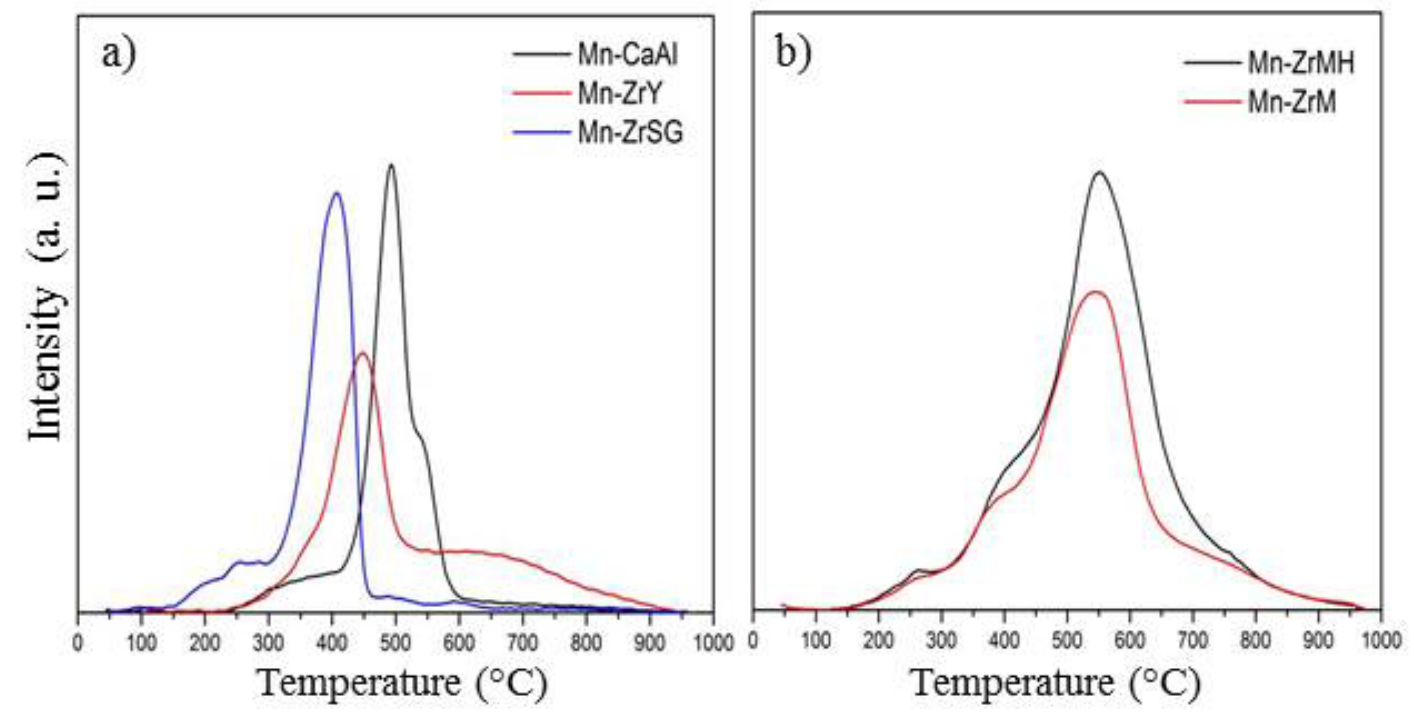

Fig. 3. Profiles of the temperature programmed reduction of the oxygen carriers prepared: a) MnCaAl, Mn-ZrY and Mn-ZrSG; b) Mn-ZrM and Mn-ZrMH.

XRD on oxygen carriers impregnated on the MELChemicals support showed $\mathrm{Mg}_{6} \mathrm{MnO}_{8}$ and $\mathrm{Mn}_{3} \mathrm{O}_{4}$ as active phases. The $\mathrm{Mg}_{6} \mathrm{MnO}_{8}$ reduction likely occurs in a similar way to pure $\mathrm{MnO}_{2}$, being noticed three peaks of reduction with hydrogen; see Figure $3 \mathrm{~b}$. The first one is at low temperature with a peak in $395{ }^{\circ} \mathrm{C}$. The rest were overlapping peaks located at temperatures above $500{ }^{\circ} \mathrm{C}$. It 
was found that the peak intensity at low temperature was substantially lower than those that occur at high temperatures. It was observed a reduction shoulder around $400{ }^{\circ} \mathrm{C}$, which can be attributed to the reduction of $\mathrm{Mn}^{4+}$ to $\mathrm{Mn}^{3+}$ of the superficial $\mathrm{Mg}_{6} \mathrm{MnO}_{8}$ [40]. The high intensity in the reduction temperature region from $450-800{ }^{\circ} \mathrm{C}$ may be the result of several species of manganese that have close reduction temperature, that contributed to this peak. In this region, the reduction of $\mathrm{Mn}^{3+}$ to $\mathrm{Mn}^{2+}$ can occur in two steps (Eqs. 9 and 10), as well as the reduction of free $\mathrm{Mn}_{3} \mathrm{O}_{4}$ to the $\mathrm{MnO}\left(\mathrm{Mn}_{3} \mathrm{O}_{4}\right.$ free was identified by XRD beyond the reductions of $\mathrm{Mn}^{4+}$ remaining.

$3 \mathrm{Mn}_{2} \mathrm{O}_{3}+\mathrm{H}_{2} \rightarrow 2 \mathrm{Mn}_{3} \mathrm{O}_{4}+\mathrm{H}_{2} \mathrm{O}$

$\mathrm{Mn}_{3} \mathrm{O}_{4}+\mathrm{H}_{2} \rightarrow 3 \mathrm{MnO}+\mathrm{H}_{2} \mathrm{O}$

Considering the extreme reduction conditions, in which the samples were subjected during TPR analysis, the mixed oxide was reduced, according with XRD results as follows:

$\mathrm{Mg}_{6} \mathrm{MnO}_{8}+\mathrm{H}_{2} \rightarrow 6 \mathrm{MgO}+\mathrm{MnO}+\mathrm{H}_{2} \mathrm{O}$

and that the manganese changed from $\mathrm{Mn}^{4+}$ to $\mathrm{Mn}^{2+}$ after the end of the experiment $[40,42]$.

\subsection{Reactivity of oxygen carriers}

Initially, the five prepared oxygen carriers were subjected to the reduction/oxidation cycles in order to assess their reactivity. The evaluated temperatures were 850 and $950{ }^{\circ} \mathrm{C}$. Variations in reactivity were not observed during multiple redox isothermal tests. Fig. 4 shows the results found for fifth cycle with the five manganese-based oxygen carriers, comparing the reactivity with different fuels $\left(\mathrm{H}_{2}\right.$ or $\left.\mathrm{CH}_{4}\right)$ and at different temperatures. The following reactions were considered for the mass variations found in the thermobalance for the active phases $\mathrm{Mn}_{3} \mathrm{O}_{4}$ and $\mathrm{Mg}_{6} \mathrm{MnO}_{8}$ :

$$
\begin{aligned}
& \mathrm{CH}_{4}+4 \mathrm{Mn}_{3} \mathrm{O}_{4} \rightarrow \mathrm{CO}_{2}+2 \mathrm{H}_{2} \mathrm{O}+12 \mathrm{MnO} \\
& \alpha \mathrm{CH}_{4}+4 \mathrm{Mg}_{6} \mathrm{MnO}_{8} \rightarrow \alpha \mathrm{CO}_{2}+2 \alpha \mathrm{H}_{2} \mathrm{O}+4 \mathrm{Mg}_{6} \mathrm{MnO}_{8-\alpha} \\
& \mathrm{H}_{2}+\mathrm{Mn}_{3} \mathrm{O}_{4} \rightarrow \mathrm{H}_{2} \mathrm{O}+3 \mathrm{MnO}
\end{aligned}
$$


$\alpha \mathrm{H}_{2}+\mathrm{Mg}_{6} \mathrm{MnO}_{8} \rightarrow \alpha \mathrm{H}_{2} \mathrm{O}+\mathrm{Mg}_{6} \mathrm{MnO}_{8-\alpha}$

$6 \mathrm{MnO}+\mathrm{O}_{2} \rightarrow 2 \mathrm{Mn}_{3} \mathrm{O}_{4}$

$\mathrm{Mg}_{6} \mathrm{MnO}_{8-\alpha}+(\alpha / 2) \mathrm{O}_{2} \rightarrow \mathrm{Mg}_{6} \mathrm{MnO}_{8}$

According to the results presented in Fig. 4 the better results for the $\mathrm{Mn}$-CaAl material corresponded to $\mathrm{H}_{2} 950^{\circ} \mathrm{C}$, in which about $80 \%$ of solid was converted. The results showed that the rate of oxidation was not influenced by the examined temperatures, and in all tests the carrier was regenerated at virtually the same time. For the oxygen carrier Mn-ZrY the reactivity with hydrogen gas was higher when compared with methane, at both temperatures. Similarly, the conversion achieved in $850^{\circ} \mathrm{C}$ was lower than one from $950{ }^{\circ} \mathrm{C}$, needing in both cases around $60 \mathrm{~s}$ to achieve the maximum reduction. The reactivity of $\mathrm{Mn}$ - $\mathrm{ZrSG}$ with $\mathrm{H}_{2}$ and $\mathrm{CH}_{4}$ was nearly identical, reaching conversions around $90 \%$, in both reduction and oxidation, in a time lower than 30 seconds in all cases analyzed. For the carriers $\mathrm{Mn}-\mathrm{ZrMH}$ and $\mathrm{Mn}-\mathrm{ZrM}, \mathrm{Mn}_{3} \mathrm{O}_{4}$ and $\mathrm{Mg}_{6} \mathrm{MnO}_{8}$ were identified as active phases. For $\mathrm{Mn}_{3} \mathrm{O}_{4}$ the reactions happen according to the Eq. 12,14 and 16. While, Eqs. 13, 15 and 17 represent the reactions that occurred with the active phase $\mathrm{Mg}_{6} \mathrm{MnO}_{8}$ (where $\alpha$ is $<1$ ).

$\mathrm{Mn}-\mathrm{ZrMH}$ oxygen carrier at $950{ }^{\circ} \mathrm{C}$ reached a conversion around $90 \%$ in less than 180 s with fuel gas $\left(\mathrm{H}_{2}\right.$ and $\left.\mathrm{CH}_{4}\right)$ and the oxidation happens quickly up to $100 \mathrm{~s}$, and then very slowly, indicating that the active phase presents some difficulty to fully regenerate to its initial state. The experiments performed at $850{ }^{\circ} \mathrm{C}$, with hydrogen the carrier conversion was $100 \%$ while with methane was $82 \%$. Oxidations at $850{ }^{\circ} \mathrm{C}$ have similar behaviour to the oxidations at $950{ }^{\circ} \mathrm{C}$, where neither the temperature nor the gas reducer gives to step changes in the oxidation of this material. For Mn-ZrM the conversion with hydrogen was the same at both analysed temperatures (100\%), while for methane it ranged around $85 \%$ and $74 \%$ at $850{ }^{\circ} \mathrm{C}$ and $950{ }^{\circ} \mathrm{C}$, respectively. All oxidations had similar behaviour, where almost all the oxidation occurs very quickly, up to $50 \mathrm{~s}$, and later a small fraction of the oxidation occurs slowly indicating a change in the controlling step. 
a) $950^{\circ} \mathrm{C}\left(\mathrm{H}_{2}\right)$

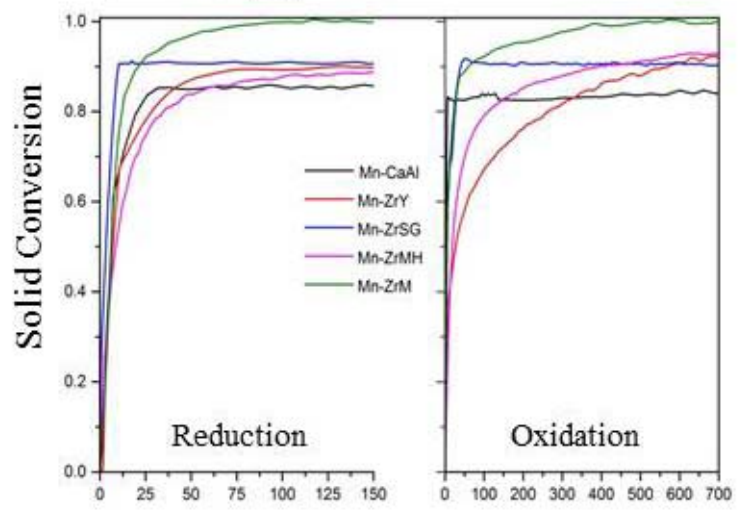

c) $850^{\circ} \mathrm{C}\left(\mathrm{H}_{2}\right)$

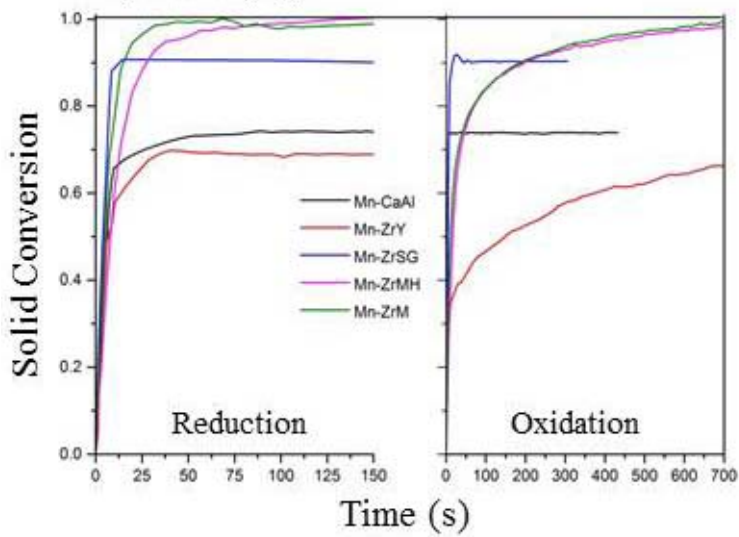

b) $950^{\circ} \mathrm{C}\left(\mathrm{CH}_{4}\right)$

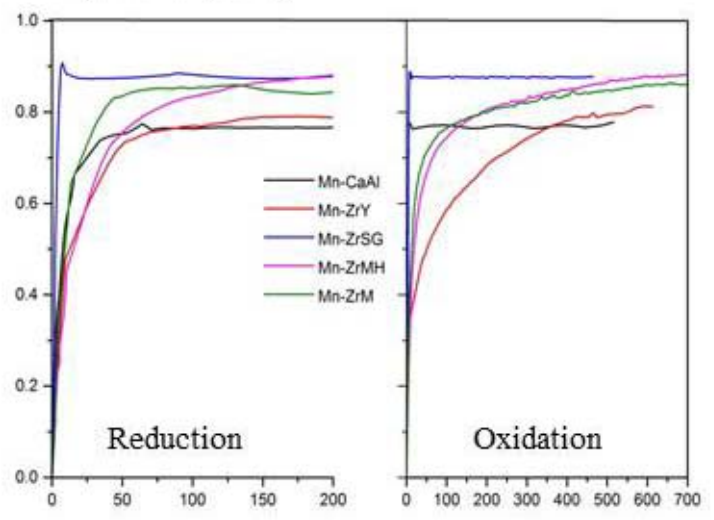

d) $850^{\circ} \mathrm{C}\left(\mathrm{CH}_{4}\right)$

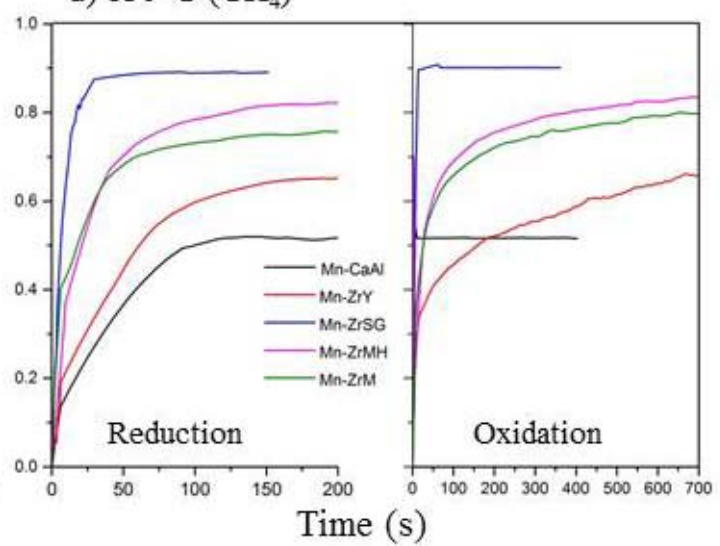

Fig. 4. Conversion of oxygen carriers by thermogravimetry for the first cycle with fresh oxygen carriers: a) $\mathrm{T}=950^{\circ} \mathrm{C}$, using $\mathrm{H}_{2}$ as the reducer; b) $\mathrm{T}=950{ }^{\circ} \mathrm{C}$, using $\mathrm{CH}_{4}$ as the reducer; c) $\mathrm{T}=850^{\circ} \mathrm{C}$, using $\mathrm{H}_{2}$ as the reducer; and d) $\mathrm{T}=850^{\circ} \mathrm{C}$, using $\mathrm{CH}_{4}$ as the reducer. All the oxidations were with synthetic air.

\subsection{Screening of oxygen carriers}

A preliminary screening was made considering that the oxygen carrier must have sufficient crushing strength $(>1 \mathrm{~N})$, high reactivity and to reach the maximum possible conversion. From the analysed results, it was found that from the five carriers studied only two of them could be considered satisfactory ( $M n-Z r S G$ and Mn-ZrM). These oxygen carriers were further tested by TGA and batch fluidized bed reactor for 100 redox cycles to know if reactivity was maintained. 


\subsubsection{Reactivity by 100 cycles of reduction/oxidation}

The selected Mn-ZrM and Mn-ZrSG oxygen carriers were subjected to 100 cycles of reduction/oxidation in a thermobalance, in order to analyse the reactivity of these materials throughout multiple redox cycles; see Fig. 5 . The reducing gas was composed of $15 \% \mathrm{CH}_{4}+20 \%$ $\mathrm{H}_{2} \mathrm{O}+65 \% \mathrm{~N}_{2}$. Synthetic air was used as oxidizing agent and pure nitrogen to purge the system between oxidation and reduction steps. Reduction and oxidation were carried out at the temperature of $950^{\circ} \mathrm{C}$. Each reduction/oxidation step was of $60 \mathrm{~s}$, followed by $30 \mathrm{~s}$ of purge.
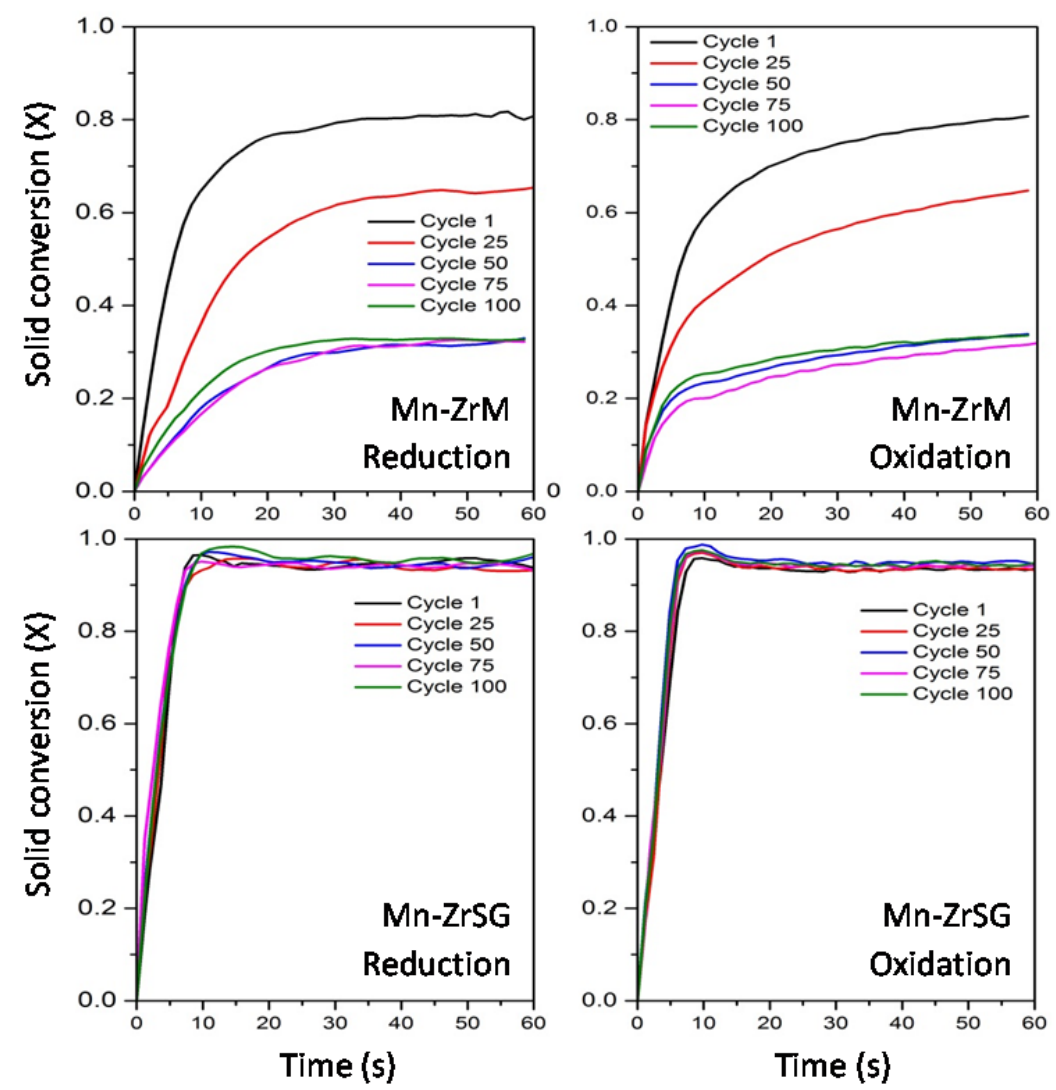

Fig. 5. Conversion achieved with Mn-ZrM and Mn-ZrSG materials during 100 redox cycles. Reduction: $15 \% \mathrm{CH} 4+20 \% \mathrm{H} 2 \mathrm{O}$; Oxidation: air; Reacting temperature: $950 \stackrel{\circ}{ } \mathrm{C}$.

During 100 cycles, the Mn-ZrM material initially presented a high conversion ( $80 \%$ ), with a gradual decrease of the solid conversion, decreasing until $30 \%$ in the $50^{\text {th }}$ cycle, indicating one important deactivation. On the other hand, the oxygen carrier Mn-ZrSG presented very fast 
reaction rate in both the reduction and oxidation steps, reaching about $95 \%$ of its total oxygen transport capacity in less than $10 \mathrm{~s}$. These results showed that the Mn-ZrSG particles are quite reactive with methane and maintained the reactivity over the 100 cycles of reduction/oxidation.

\subsubsection{Reactivity in fluidized bed batch reactor}

Mn-ZrM material also was evaluated in fluidized bed batch reactor, although it presented serious agglomeration problems during fluidization in the initial experiments conducted. By this reason, the material was considered unfeasible to proceed with the scheduled tests and it was rejected for use in CLC.

Mn-ZrSG oxygen carrier was initially tested with methane at temperatures from 850 to $950{ }^{\circ} \mathrm{C}$. Fig. 6 shows the product distribution during redox cycles (no 1 and 20). At all the temperatures tested the $\mathrm{CH}_{4}$ conversion was not complete. The $\mathrm{CH}_{4}$ slip decreased with temperature, although it was important even at $950^{\circ} \mathrm{C}$. The gas product distribution showed significant concentrations of $\mathrm{CO}$ and $\mathrm{H}_{2}$ at the reactor outlet. $\mathrm{CO}$ and $\mathrm{CO}_{2}$ appeared also during oxidation indicating the $\mathrm{C}$ deposition during the reduction step. The maximum conversion of $\mathrm{CH}_{4}$ at $950{ }^{\circ} \mathrm{C}$ was found during the first cycle. In this Figure, a deactivation of the oxygen carrier with the number of redox cycles is also observed. Moreover, it can be observed that $\mathrm{O}_{2}$ concentration does not return quickly to its initial value during oxidation. This slow increase indicates that oxidation was slow and not complete. Unconverted $\mathrm{CH}_{4}$ was always present at high concentrations together a decrease of the $\mathrm{CO}_{2}$ concentration at the outlet of the reactor and one increase in the concentrations of $\mathrm{CO}$ and $\mathrm{H}_{2}$. This was different to the results obtained during 100 redox cycles TGA, although it could be due to the insufficient oxygen carrier inventory in the batch reactor. It was not clear the possible reasons for this behaviour because, although the fluidization was not smoot, there was not observed any agglomeration in the bed. Difficulties in oxidation could contribute to the deactivation of the oxygen carrier. Samples taken from the bed maintained its oxygen transport capacity although its reactivity had an important decrease with a change in the reduction rate index from 13.1 to 5 . 


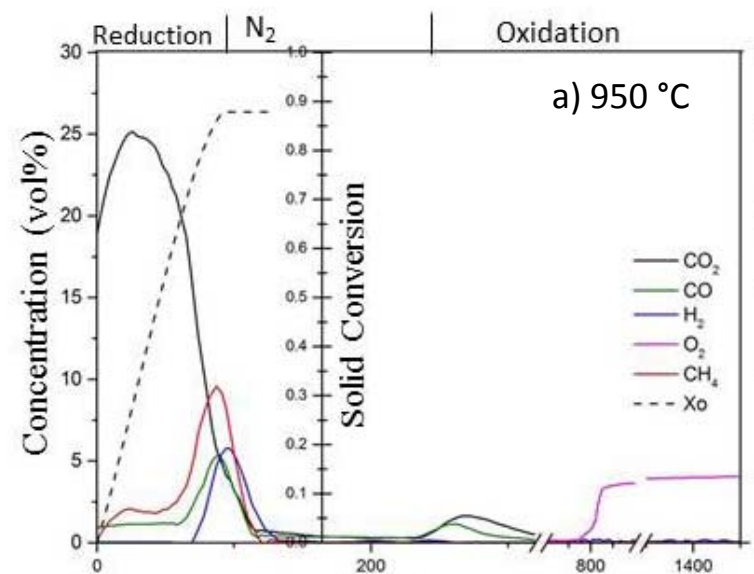

Time (s)

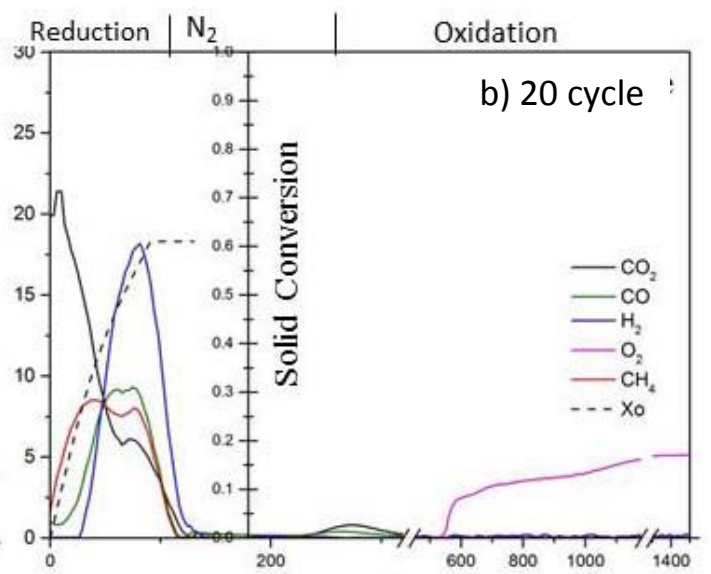

Time (s)

Fig. 6 . Gas product distribution during redox cycles in discontinuous fluidized bed reactor working with the Mn-ZrSG using $\mathrm{CH}_{4}$ as fuel: a) $1^{\text {st }}$ cycle at $950{ }^{\circ} \mathrm{C}$; b) cycle 20 at $950{ }^{\circ} \mathrm{C}$.

Moreover the oxygen carrier Mn-ZrSG was examined for the combustion of $\mathrm{H}_{2}$ and CO. The reduction reaction of manganese oxide when using $\mathrm{CO}$ or $\mathrm{H}_{2}$ as fuel is slightly exothermic [10], and an increase of $15{ }^{\circ} \mathrm{C}$ inside the reactor was observed during the reductions stage. Fig. 7 shows the gas product distribution obtained at temperatures from 800 to $950{ }^{\circ} \mathrm{C}$ using $\mathrm{CO}(50 \% \mathrm{CO}+20$ $\% \mathrm{CO}_{2}+30 \% \mathrm{~N}_{2}$ ) as fuel. At the three analysed temperatures, similar behaviour was found (Figs. 7a; $7 \mathrm{~b} ; 7 \mathrm{c})$, where initially it was seen basically $\mathrm{CO}_{2}$ concentrations, indicating that in this interval all fuel was burned. After $25 \mathrm{~s}$, the unburned CO concentrations gradually increased reaching a maximum of $10 \%$, due to the decrease in the amount of oxygen available in the oxygen carrier. During the oxidation, in the first step all the oxygen feed in was consumed in the oxidation of the oxygen carrier. The $\mathrm{O}_{2}$ concentration increased rapidly until it reached the input gas concentration. Also in the oxidation step, compounds such as $\mathrm{CO}$ and $\mathrm{CO}_{2}$ were not detected, what indicates that there was not carbon formation during the reduction stage. Multiple redox cycles were carried out to follow the possible deactivation of the oxygen carrier. Fig. $7 \mathrm{~d}$ shows the gas product distribution in the redox cycle no. 20. It was possible to observe that the particles of Mn-ZrSG oxygen carrier kept its reactivity and solid conversion after 20 redox cycles in the same 
conditions. Considering all cycles analysed for Mn-ZrSG oxygen carrier with carbon monoxide as fuel, the conversion of the solid $\left(X_{\text {red }}\right)$ in the reduction step was 0.83 .
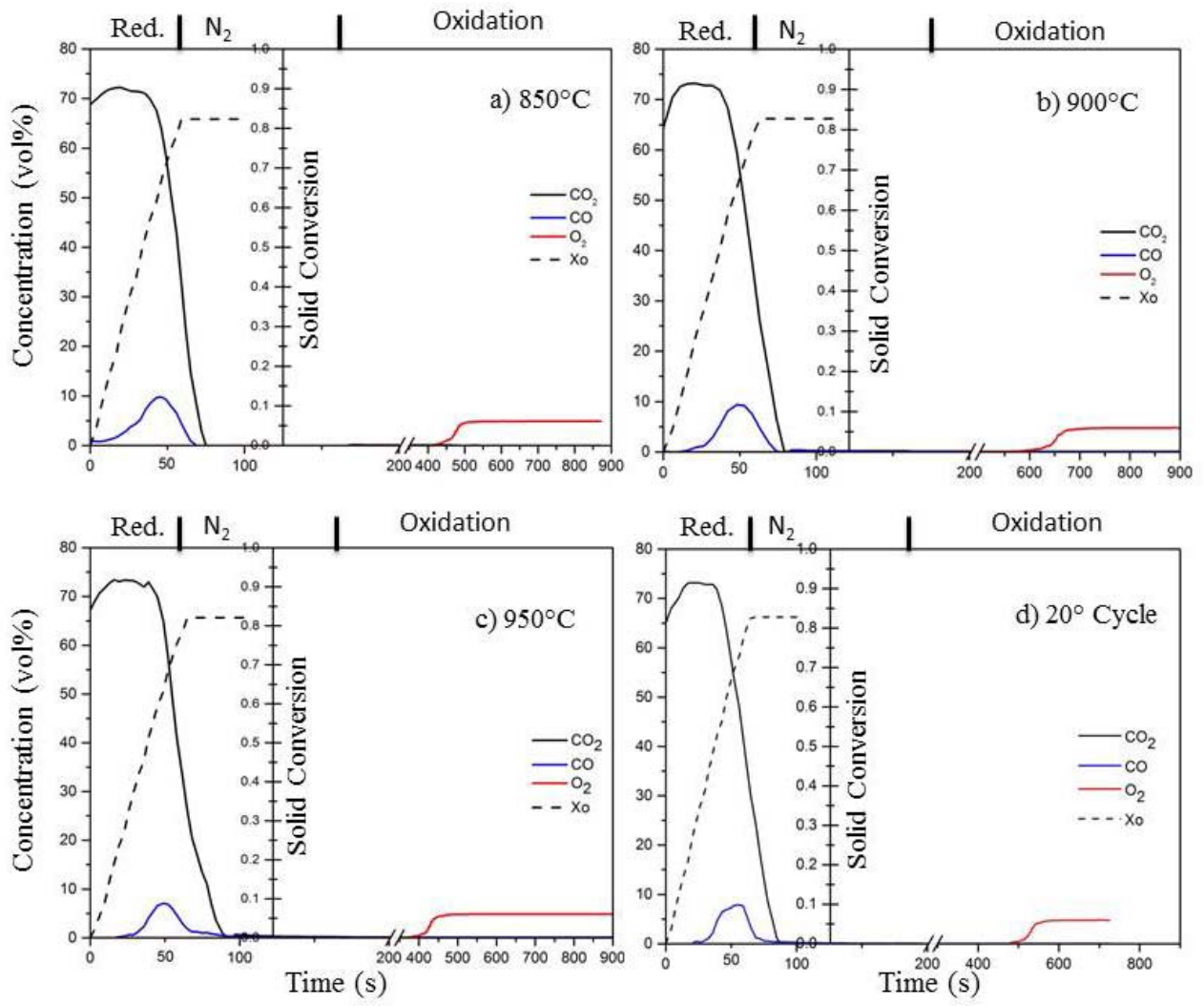

Fig. 7. Gas product distribution in the batch fluidized bed reactor working with Mn-ZrSG using CO as fuel: a) $\mathrm{T}=850^{\circ} \mathrm{C}$; b) $\mathrm{T}=900^{\circ} \mathrm{C}$; c) $950^{\circ} \mathrm{C}$ (first cycle); d) after 20 cycles at $\mathrm{T}=950^{\circ} \mathrm{C}$.

The hydrogen gas was another fuel examined in the fluidized bed batch reactor with Mn-ZrSG oxygen carrier. Fig. 8 shows the gas product distribution at the outlet of the reactor during one reduction/oxidation cycle of Mn-ZrSG, using hydrogen in different conditions. It turns out that the redox cycles behaviour were virtually equal at the three temperatures, where nearly the whole reduction period the conversion of $\mathrm{H}_{2}$ to generate $\mathrm{H}_{2} \mathrm{O}$ occurred, since no hydrogen gas concentration was observed until the last steps of the reduction. The increasing concentrations of $\mathrm{H}_{2}$ at the end of the reduction (after $60 \mathrm{~s}$ ) were attributed to low concentrations of the active phase, $\mathrm{Mn}_{3} \mathrm{O}_{4}$, when the oxygen carrier conversion was higher than $50 \%$. This does not occur in a continuous circulating fluidized bed CLC system where the supply of the oxidized oxygen carrier 
$\left(\mathrm{Mn}_{3} \mathrm{O}_{4}\right)$ is constant. During most part of the oxidation, the oxygen concentration was zero, because it was completely consumed in the regeneration of the oxygen carrier, while its velocity was limited by the oxygen supply to the reactor.
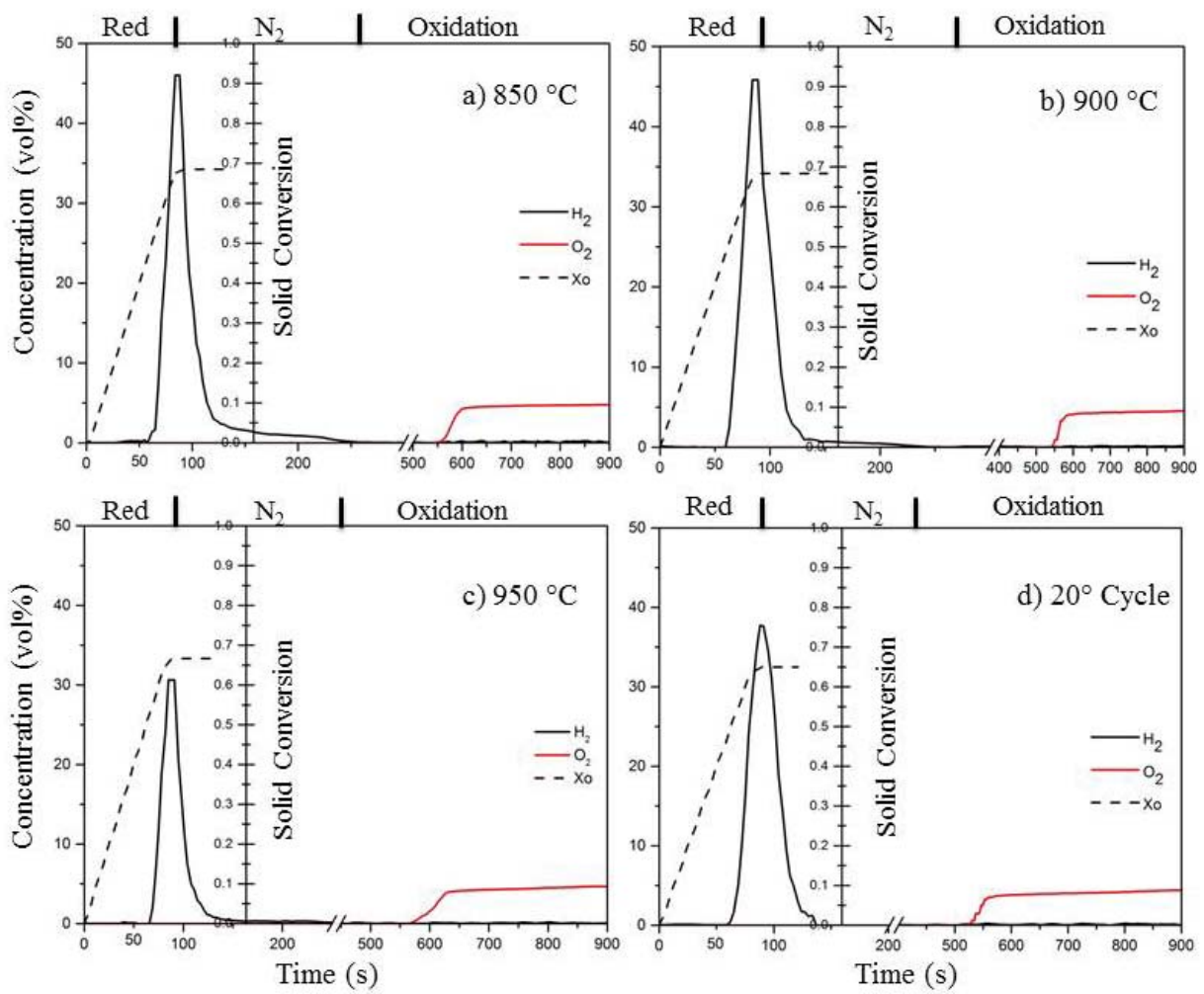

Fig. 8. Distribution of the gaseous products in the discontinuous fluidized bed reactor working with the carrier Mn-ZrSG using hydrogen gas as fuel: a) $850^{\circ} \mathrm{C}$; b) $900^{\circ} \mathrm{C}$; c) $950{ }^{\circ} \mathrm{C}$; d) after 20 cycles at $950^{\circ} \mathrm{C}$.

Moreover the reactivity of Mn-ZrSG was evaluated during 20 reduction/oxidation cycles at $950{ }^{\circ} \mathrm{C}$ with hydrogen. Fig. 8d shows the gas product distribution during the redox cycle no. 20. In all redox cycles using $\mathrm{H}_{2}$ as fuel, it was found that this carrier kept its reactivity with hydrogen gas. The solid conversion during the reduction step was 0.68 .

The formation of carbon on the oxygen carrier particles can be a problem, since it can deactivate the material, to produce some agglomeration problems and mainly it decrease the efficiency of $\mathrm{CO}_{2}$ capture because in the $\mathrm{CLC}$ unit $\mathrm{C}$ is transferred together the oxygen carrier to the air reactor in which it is oxidized to $\mathrm{CO}_{2}$ and emitted to the atmosphere. In all the experimental work with 
methane gas at $950{ }^{\circ} \mathrm{C}$ with Mn-ZrSG, it was found in all the 20 cycles the generation of $\mathrm{CO}$ and $\mathrm{CO}_{2}$ during the oxidation step. Similar behaviour was found at lower temperatures. In all the oxidation cycles, the concentration of carbon monoxide and carbon dioxide were lower than $2 \%$. However, in any experiment carried out with $\mathrm{CO}$ as fuel it was not noticed the formation of carbon during the reduction period.

\subsubsection{Fluidization behaviour}

As it was previously indicated, Mn-ZrM material presented serious problems of agglomeration and fluidization during batch fluidized bed tests. However during all the testing time with $\mathrm{Mn}$ ZrSG oxygen carrier, about 74 hours, the pressure drop in the bed was kept almost constant indicating that agglomeration problems were not present, although fluidization was not smooth with $\mathrm{CH}_{4}$. Moreover, Mn-ZrSG particles extracted at the end of the tests did not showed any evidence of agglomeration. To determine the attrition rate of the oxygen carrier during redox cycles, 60 reduction/oxidation cycles were performed under fluidization conditions, during 39 hours of fluidization. In all redox cycles methane gas was used as reducer, oxygen as oxidant gas $\left(5 \% \mathrm{O}_{2}\right)$ and pure nitrogen to purge the system. Fig. 9 shows the attrition rate as a function of time, for the oxygen carrier Mn-ZrSG.

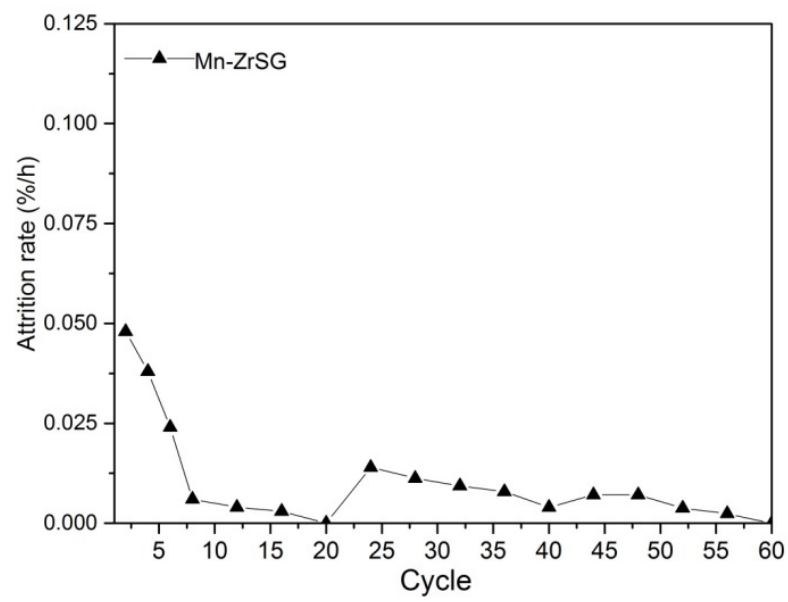

Fig. 9. Attrition rate of the Mn-ZrSG oxygen carrier during multi-cycle reaction in the fluidized bed during 39 hours of operation (60 redox cycles). 
A greater attrition rate occurred during the first two cycles, which can be attributed to the rounding effect of particle irregularities. After the $20^{\text {th }}$ cycle, a small increase in the attrition loss occurred, that can be associated to the fragmentation and/or attrition on the surface of the particles. It is important to notice that the Mn-ZrSG oxygen carrier presented a very low attrition rate. Considering all the testing done the attrition rate was 0.009 weight \%/hour, which corresponds to an average operation lifetime for the Mn-ZrSG particles of more than 11000 hours, what is a high value when compared to other oxygen carriers reported in the literature $[8,43]$

\subsection{Characterization after redox cycles}

\subsubsection{X-ray Difraction (XRD)}

In Fig. 10a the diffractograms obtained for the Mn-ZrM oxygen carrier fresh and after the experiments in batch fluidized bed reactor are presented. Not agglomerated particles and other ones taken from agglomerates were analysed. It was possible to notice significant differences in the obtained diffractograms, highlighting the decrease of peaks that were related with $\mathrm{MgAl}_{2} \mathrm{O}_{4}(2$ theta in $16.3 ; 30.7 ; 36.3 ; 44.1 ; 58.4$ and $64.3^{\circ}$ ) by comparing the samples fresh and after the experiments at the reactor. Comparing the particles tested in the reactor in a similar way, it was possible to observe a greater amount of peaks characteristic related with the $\mathrm{Mg}_{6} \mathrm{MnO}_{8}$ structure on the agglomerated particle with values of 2 theta in $18.4 ; 35.5$ and $57.3^{\circ}$. After redox cycles, significant structural changes in Mn-ZrM material occurred, as proved by the differences in the peaks and their corresponding intensities, which indicate a greater concentration of manganese oxides in the agglomerated particles. This is in accordance with the TPR and SEM results, which will be presented later. 
a) $\mathrm{Mn}-\mathrm{ZrM}$

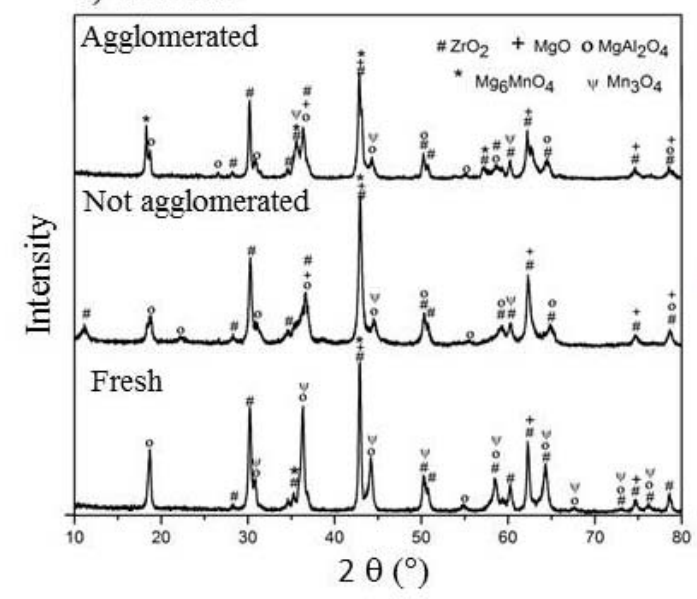

b) Mn-ZrSG

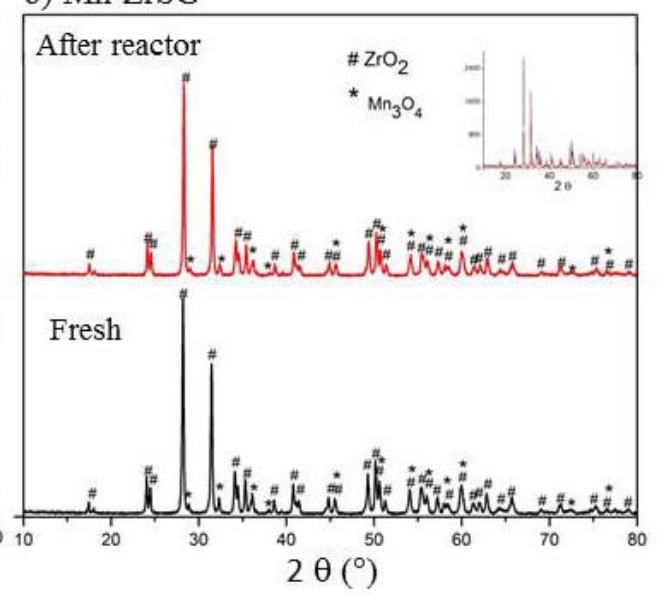

Fig. 10. X-ray diffraction for oxygen carriers fresh and after the experiments in the reactor: a) MnZrM and b) Mn-ZrSG.

For Mn-ZrSG oxygen carrier, fresh and after all the experiments in the reactor, the same crystalline structures were identified, which are: $\mathrm{ZrO}_{2}$ with monoclinic structure, and the $\mathrm{Mn}_{3} \mathrm{O}_{4}$ with tetragonal structure; see Fig. 10b. The intensities of the diffraction peaks were virtually the same. This highlights the excellent ability of Mn-ZrSG oxygen carrier in maintaining its crystalline structure after several reduction/oxidation cycles and hours of operation.

\subsubsection{Temperature programmed of reduction}

Fig. 11 shows temperature programmed reduction profiles of Mn-ZrM and Mn-ZrSG, both fresh and after the experiments in the reactor. For Mn-ZrM material (Fig. 10a) different behaviour can be observed between the fresh and agglomerated or not agglomerated particles, proving that samples were substantially modified. Both, agglomerated or non-agglomerated samples, presented a significant decrease in the amount of $\mathrm{H}_{2}$ consumption, compared with that consumed by the fresh particles. This decrease in hydrogen consumption changed from 15 to $60 \%$, between agglomerated and non-agglomerated particles. 


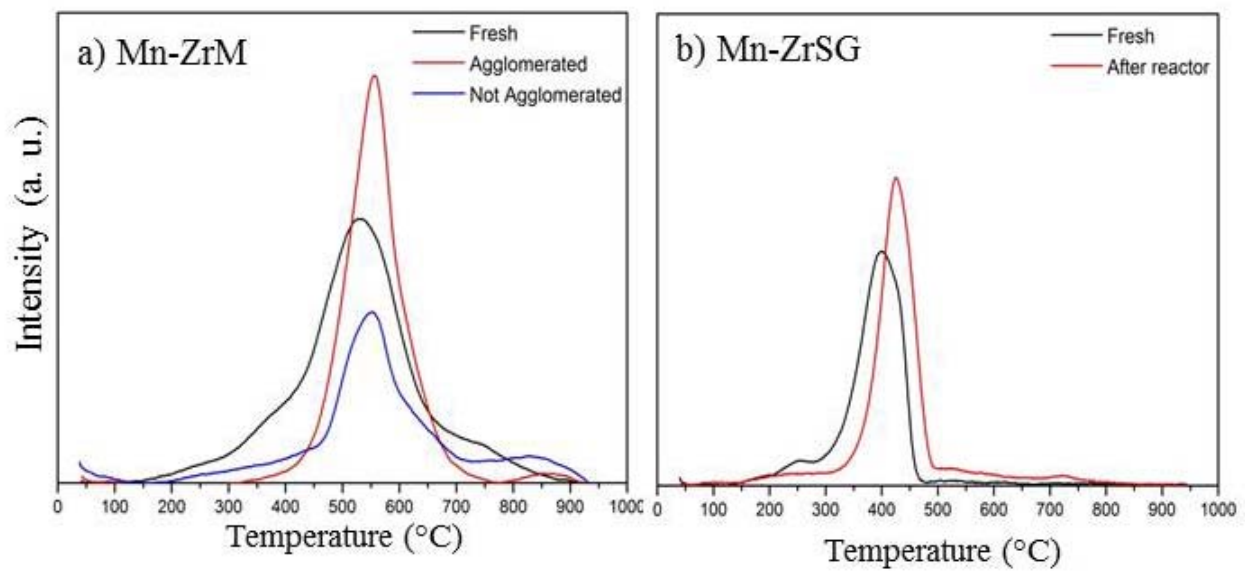

Fig. 11. Temperature programmed reduction for oxygen carriers fresh and after reactor experiments: a) Mn-ZrM and b) Mn-ZrSG.

In Fig. $11 \mathrm{~b}$ it was observed that the oxygen carrier Mn-ZrSG after 74 hours of operation in a fluidized bed batch reactor, kept its reducing behaviour, with only a slight variation of the temperature. Furthermore, the hydrogen consumption was the same for particles fresh and after the tests in the reactor, and maintained the same oxygen transport capacity.

\subsubsection{Scanning Electron Microscopy (SEM)}

Fig. 12 shows micrographs of the Mn-ZrM material fresh and after the tests in the reactor. It can be observed the presence of agglomerated particles in Fig. 12b, which were responsible for the de-fluidization of the system and for the decrease in reactivity of this material. The agglomerated material was composed mainly by smaller material particles stuck. The morphology of the fresh particles and of those that did not agglomerate in the reactor was similar. The chemical microanalysis by energy dispersive spectroscopy (EDX) showed a greater superficial concentration of manganese in the particle that was agglomerated (Fig. 12b), corroborating the assumption that the manganese oxides migrated to the surface and between particles. 
a) Fresh
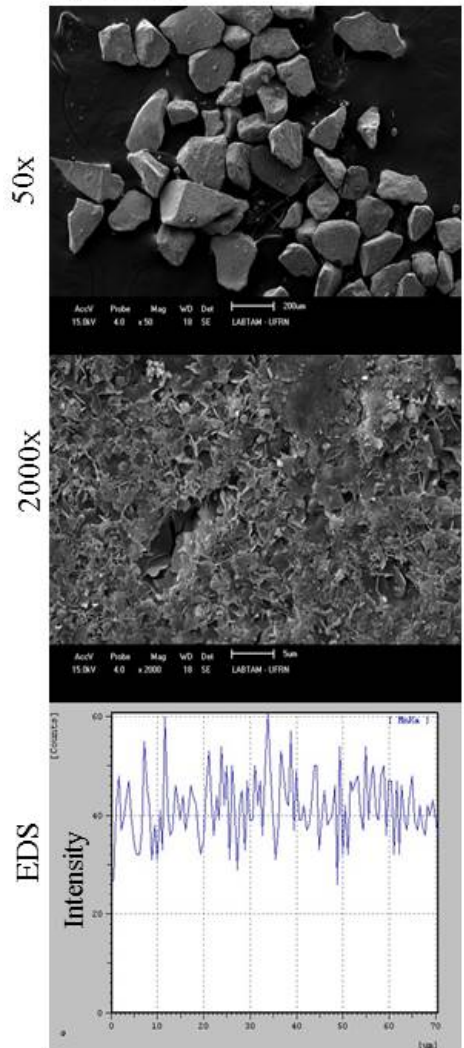

b) Agglomerated
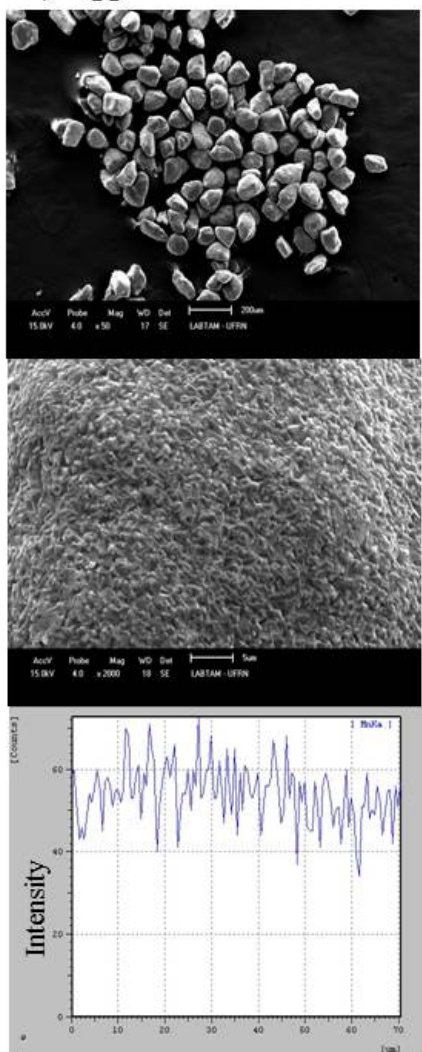

c) Not agglomerated
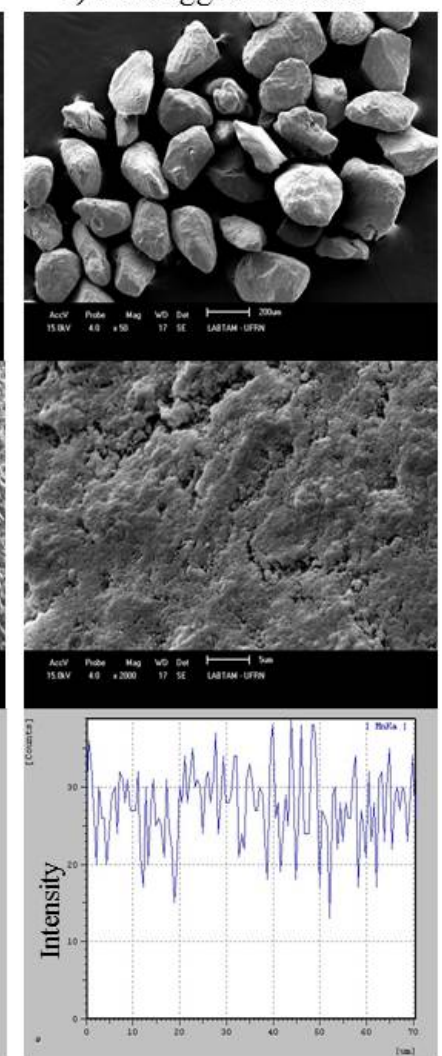

Fig. 12. Scanning Electron Microscopy of the Mn-ZrM oxygen carrier, fresh and after the experiments in the reactor: a) fresh; b) agglomerated particles and c) non-agglomerated particles.

Fig. 13 shows the micrographs obtained for Mn-ZrSG oxygen carrier, fresh and after the experiments performed in the batch fluidized bed reactor. According to Fig. 13, the morphology of particles, fresh and after the experiments in the fluidized bed reactor, were similar, with rounded aspect and almost identical sizes. One higher superficial concentration of manganese in particles tested in the reactor was observed by EDX. This migration happened from the inner to the external surface of the particles during operation at high temperature in the reactor. 

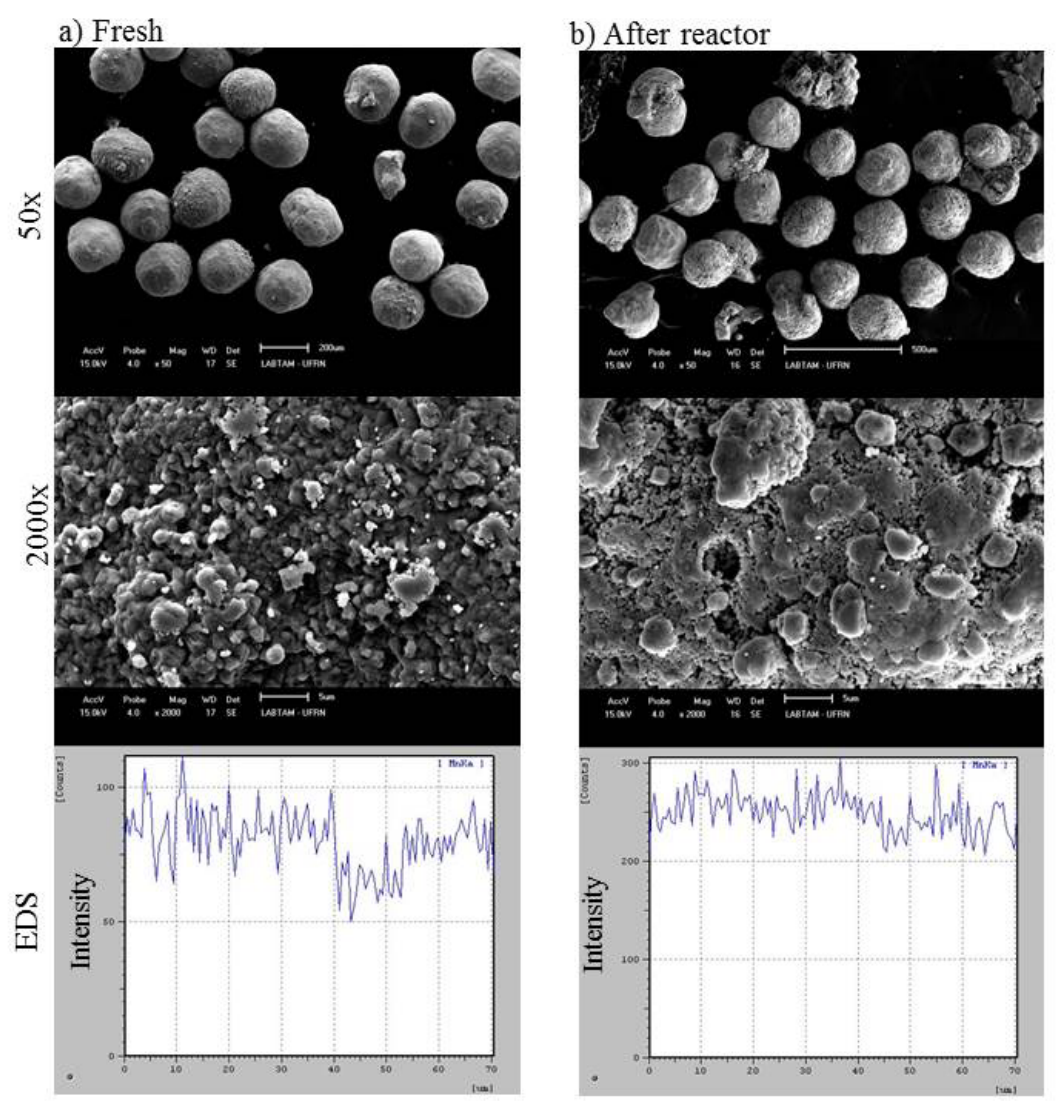

Fig. 13. Scanning Electron Microscopy and EDX profiles of the Mn-ZrSG oxygen carrier submitted in reactor: a) fresh; b) after the experiments.

\section{Discussion}

The results of XRD and TPR showed that Mn-CaAl, Mn-ZrY and Mn-ZrSG oxygen carriers formed as active phase $\mathrm{Mn}_{3} \mathrm{O}_{4}$, which was in accordance with the reports from the literature and thermodynamic data $[6,9-12]$. On the other hand, MELChemicals support which has in its composition $\mathrm{MgO}$, (originated from hydrotalcite), favoured the solid state reaction with manganese oxide, during calcination at $950{ }^{\circ} \mathrm{C}$, forming a mixture of manganese oxides: $\mathrm{Mg}_{6} \mathrm{MnO}_{8}$ and $\mathrm{Mn}_{3} \mathrm{O}_{4}$ as active phases. The advantage of the mixed oxide $\mathrm{Mg}_{6} \mathrm{MnO}_{8}$ was its ability to provide gaseous oxygen, similar to $\mathrm{MnO}_{2}$. It was verified that high $\mathrm{Mg} / \mathrm{Mn}$ molar ratios, when calcined in air at temperatures above $800{ }^{\circ} \mathrm{C}$, improved the formation of the $\mathrm{Mg}_{6} \mathrm{MnO}_{8}[38,39]$ compound. 
The material Mn-CaAl showed a crushing strength lower than $1 \mathrm{~N}$, although it presented high reaction rates $(\% / \mathrm{min})$ and the maximum conversion reached at $850{ }^{\circ} \mathrm{C}$ was of $73 \%$. Because of this, the oxygen carrier Mn-CaAl was not further considered.

The carrier Mn-ZrY showed the greatest value of crushing strength (7.3 N). On the other hand, its reactivity with reducing gases was low, especially at $850^{\circ} \mathrm{C}$, which could be attributed to the no complete reduction of $\mathrm{Mn}_{3} \mathrm{O}_{4}$ under the examined conditions, as it was verified by the TPR experiments. Moreover the oxidation was slow which makes difficult the oxygen carrier regeneration. As a consequence, the values of the rate indexes for reduction and oxidation were the lower ones found between all the prepared oxygen carriers. By the above reasons this oxygen carrier was not selected for further investigations.

These reactivities were higher than that of the $\mathrm{Mn}_{3} \mathrm{O}_{4} / \mathrm{ZrO}_{2}$ oxygen carrier obtained by mechanical mixing [15]. The slow re-oxidation found for $\mathrm{Mn}-\mathrm{ZrMH}$ and $\mathrm{Mn}-\mathrm{ZrM}$ oxygen carriers, was associated to the active phase $\mathrm{Mg}_{6} \mathrm{MnO}_{8}$. This was attributed to the partial destruction of the spinel structure of the mixed oxide when it was reduced under the conditions examined, resulting in $\mathrm{MgO}$ and $\mathrm{MnO}$ formation (Eq. 11). However the regeneration to $\mathrm{Mg}_{6} \mathrm{MnO}_{8}$ in air at high temperatures occurs slowly and it was not complete. It was reported that some mixed oxides, such as calcium manganese perovskites, with $\mathrm{Mn}(\mathrm{IV})$ in the structure should be reduced up to +3 , to preserve the perovskite structure of the active phase [44]. Similarly, it is believed that the $\mathrm{Mg}_{6} \mathrm{MnO}_{8}$ should be reduced only to a certain level to keep its structure and facilitate the regeneration, although this fact that needs to be confirmed.

Oxygen carriers $\mathrm{Mn}-\mathrm{ZrMH}$ and $\mathrm{Mn}-\mathrm{ZrM}$ presented crushing strength values higher than $3 \mathrm{~N}$ and the largest oxygen transport capacity among the prepared materials. The maximum conversion reached by these two oxygen carriers was quite similar and the rate index for reduction was slightly higher for Mn-ZrM. During multiple redox cycles by TGA with Mn-ZrM, it was verified that the oxidation step controlled the reactivity of the oxygen carrier because when the $\mathrm{Mg}_{6} \mathrm{MnO}_{8}$ phase is reduced it cannot return completely to its initial conversion during the oxidation; and/or 
the residence time in the oxidation was not high enough to recover the active phase. These reasons drive to a decrease in the amount of oxygen available to each subsequent cycle, leading to a decreased conversion of the oxygen carrier until the stabilization. This fact can be assigned to the early reaction rate to be controlled by chemical reaction, and later, when most of the particles had reacted, the reaction can be controlled by the solid diffusion [12]. Moreover during batch fluidized bed reactor tests, defluidization of the bed was observed which was originated by the agglomeration of the oxygen carrier particles. By this reason Mn-ZrM was not considered as suitable for CLC.

Mn-ZrSG oxygen carrier had a sufficient crushing strength ( $2.5 \mathrm{~N}$ ) well above $1 \mathrm{~N}$. Mn-ZrSG oxygen carrier presented high reduction and oxidation reactivities reaching the maximum conversion in less than 30 seconds. During all tests the maximum conversion reached during oxidation and reduction steps were around $90 \%$ and the rate indexes found for reduction and oxidation were high, 13.1 and 8.5 respectively at $950{ }^{\circ} \mathrm{C}$. During multiple redox cycles (100 cycles) by TGA, the reactivity, the maximum redox conversion and the physic-chemical properties were maintained, as it was verified in the XRD, TPR and SEM. The above results make this oxygen carrier as a promising material for CLC processes and it was qualified for more advanced studies.

However a different behaviour was found for Mn-ZrSG oxygen carrier when it was tested with methane in the batch fluidized bed reactor. Results indicated the low reactivity of the carrier with a non-complete $\mathrm{CH}_{4}$ conversion and the formation of carbon in all the conditions tested. Reactivity after reaction was reduced showing a rate index of 5.2 but the oxygen transport capacity was maintained. This indicates that higher bed inventories were needed to reach complete $\mathrm{CH}_{4}$ conversion. Product distribution was not adequate for Chemical Looping Combustion of $\mathrm{CH}_{4}$ because always $\mathrm{CO}$ and $\mathrm{H}_{2}$ appeared after short periods of reduction. Moreover, both $\mathrm{CO}$ and $\mathrm{H}_{2}$ concentrations increased and the initial time for appearance was shortened with the number of redox cycles, indicating some deactivation of the oxygen carrier. These differences with TGA results cannot be attributed to in-bed agglomeration problems and 
could be likely due to the uncomplete oxidation, although a further investigation is needed to clarify the reasons for this behaviour.

Experiments performed with Mn-ZrSG and carbon monoxide as fuel, presented good performance. CO burning efficiency increased with temperature and one solid conversion as high as 0.83 in all cycles was found. During the main part of the reduction step all CO was converted to $\mathrm{CO}_{2}$. After this period, $\mathrm{CO}_{2}$ concentrations decreased while the $\mathrm{CO}$ increased. This change in the reduction was associated with the conversion degree of the oxygen carrier and the lattice oxygen availability. However in a continuous reactor it is not expected unburned $\mathrm{CO}$ at the outlet, since the supply of oxidized Mn-ZrSG will be constant, and the appearance of the CO is produced by reduction of active phase $\left(\mathrm{Mn}_{3} \mathrm{O}_{4}\right)$ in the last reduction stages. Moreover, in these experiments it was not possible to verify carbon deposition in any condition evaluated, indicating that this carrier did not favour solid carbon formation reactions from the $\mathrm{CO}$ nor by inverse Boudouard reaction $\left(2 \mathrm{CO} \rightarrow \mathrm{C}+\mathrm{CO}_{2}\right)$.

Using hydrogen gas as fuel, during the first $60 \mathrm{~s}$, the combustion of $\mathrm{H}_{2}$ was $100 \%$ and in all analysed cycles the conversion of the solid was constant, 0.68 , not being influenced by the temperature nor the cycle number. At the end of reduction, the concentration of hydrogen increases quickly. The above results indicated the suitability of Mn-ZrSG oxygen for combustion of mixtures $\left(\mathrm{CO}+\mathrm{H}_{2}\right)$ and for solid fuel CLC. Thus, this oxygen carrier is considered suitable for gas combustion, especially for syngas combustion. For $\mathrm{CH}_{4}$, although the material was highly reactive, some further investigations are needed to explain results found in the batch fluidized bed reactor that mainly could be attributed to a loss of reactivity originated by uncomplete oxidation. Likely, difficulties in the bed fluidization that did not reach bed agglomeration could partially explain this behaviour.

To put in context the reactivity of the selected oxygen carrier, it was made a comparison with different $\mathrm{Mn}$ based oxygen carriers tested in the literature showing rate indexes. Table 4 shows the rate indexes with $\mathrm{CH}_{4}, \mathrm{CO}$ and $\mathrm{H}_{2}$ together the crushing strength (CS) and the lifetime of $\mathrm{Mn}$ 
based oxygen carriers both synthetic $\left(\mathrm{Mn}_{3} \mathrm{O}_{4}, \mathrm{Mg}-\mathrm{ZrO}_{2}, \mathrm{Mn}-\mathrm{Fe}\right)$ and different $\mathrm{Mn}$ ores when they are available. Considering only the reactivity through the rate indexes, rhodonite (OXMNO10A) was the oxygen carrier with higher reactivity with $\mathrm{CH}_{4}, \mathrm{CO}$ and $\mathrm{H}_{2}$. It is necessary to mention that $\mathrm{Mn}$ ores lost their reactivity with the redox cycles with very important decreases in the rate index for (MnSA, MnGBHNE, MnGBMPB, MnBr). By this, only values in brackets in Table 4 were considered. It can be observed that after some redox cycles, rate indexes with $\mathrm{CH}_{4}$ for $\mathrm{Mn}$ ores are quite low. The oxygen carrier developed $\mathrm{Mn}-\mathrm{ZrSG}$ showed relatively high rate indexes for $\mathrm{CH}_{4}, \mathrm{CO}$ and $\mathrm{H}_{2}$.

Table 4. CLC characteristics of tested natural and synthetic Mn materials.

\begin{tabular}{|c|c|c|c|c|c|c|c|}
\hline \multirow[t]{2}{*}{ Oxygen carrier } & \multirow[t]{2}{*}{ Preparation } & \multicolumn{3}{|c|}{ Rate index (\%/min) } & \multirow[t]{2}{*}{$\operatorname{CS}(\mathrm{N})$} & \multirow[t]{2}{*}{ Lifetime (h) } & \multirow[t]{2}{*}{ Ref. } \\
\hline & & $\mathrm{CH}_{4}$ & CO & $\mathrm{H}_{2}$ & & & \\
\hline Mn-ZrSG & IMP & 13.1 & 5.5 & 8.8 & 2.5 & 11000 & \\
\hline Mn77Fe & SD & 2.5 & 0.9 & 3.2 & 1.7 & 6150 & [31] \\
\hline $\mathrm{Mn}_{3} \mathrm{O}_{4} / \mathrm{Mg}-\mathrm{ZrO}_{2}$ & FG & 11.3 & --- & --- & 1.1 & 2630 & [12] \\
\hline OXMN010A & Rhodonite ore & 12 & 17.9 & 38.8 & 2.3 & 2900 & [23] \\
\hline MnSA & Ore, Shout Africa & $5.0(0.8)$ & $5.1(5.3)$ & $14.2(1.8)$ & $4.6(2.0)$ & 1600 & [25] \\
\hline MnGBHNE & Ore, Gabon & $9.2(1.3)$ & $6.4(1.4)$ & $19.2(9.0)$ & $1.8(1.4)$ & 1000 & [25] \\
\hline MnGBMPB & Ore, Gabon & $9.3(2.2)$ & $9.0(2.5)$ & $26.4(14.8)$ & $2.4(0.5)$ & 360 & [25] \\
\hline MnBR & Ore, Brasil & $12.7(1.7)$ & $8.2(3.0)$ & $20.5(12.5)$ & $1.0(0.4)$ & 150 & [25] \\
\hline Mn Alheim & Ore, Norway & 7.2 & --- & 19.8 & --- & --- & [24] \\
\hline Mn Sinai-A & Ore & 3.6 & --- & 5.4 & --- & --- & [28] \\
\hline Mn Guizhou & Ore & 11.3 & --- & 11.3 & --- & --- & [28] \\
\hline
\end{tabular}

Rate index by TGA at $950 \mathrm{C}$. Lifetime calculated from batch fluidized bed reactor. Preparation- IMP: Impregnated; SD: spray drying; FG freeze granulation. In brackets properties after several redox cycles 
The main advantage of $\mathrm{Mn}$-ZrSG comes from the presence of $\mathrm{ZrO}_{2}$ as support for impregnation that drives to a lifetime as high as $11000 \mathrm{~h}$. This lifetime is very high in comparison with the synthetic $\mathrm{Mn}_{3} \mathrm{O}_{4}-\mathrm{ZrO}_{2}$ [9]. With respect to $\mathrm{Mn}$-Fe that has a relatively high lifetime (6150 h) the developed material has much higher reactivity with $\mathrm{CH}_{4}, \mathrm{CO}$ and $\mathrm{H}_{2}$. Moreover, $\mathrm{Mn}$ ores examined in the literature showed significant attrition rates driving to calculated lifetimes ranging from 150 to $1600 \mathrm{~h}$. Only rhodonite (OXMNO10A) oxygen carrier had high reactivity and one high lifetime of 2900 h.

Mn-ZrSG showed during TGA tests good reactivities with $\mathrm{CH}_{4}, \mathrm{CO}$ and $\mathrm{H}_{2}$ and maintained the reactivity with the redox cycles. Moreover during batch fluidized bed reactor redox cycles excellent performance was found burning $\mathrm{CO}$ and $\mathrm{H}_{2}$ showing very low attrition rates with calculated lifetimes around 11000 hours. Thus this oxygen carrier can be considered suitable for CLC, specially for syngas combustion and solid fuel chemical looping through in-situ gasification chemical looping (iG-CLC).

\section{Conclusions}

In this work five impregnated oxygen carriers, with manganese oxide as their active phase and three commercial supports based on zirconia and synthetic calcium aluminate, were prepared and their behaviour for CLC was examined by TGA, batch fluidized bed reactor, TPR, SEM-EDX and XRD.

$\mathrm{Mn}$-CaAl, $\mathrm{Mn}-\mathrm{ZrY}$ and $\mathrm{Mn}-\mathrm{ZrSG}$ oxygen carriers, presented the $\mathrm{Mn}_{3} \mathrm{O}_{4}$ active phase, while for $\mathrm{Mn}$ ZrM and $\mathrm{Mn}$-ZrMH active phases were mixed oxide $\mathrm{Mg}_{6} \mathrm{MnO}_{8}$ and $\mathrm{Mn}_{3} \mathrm{O}_{4}$. After preliminary screening two carriers (Mn-ZrM and Mn-ZrSG) were subjected to multiple redox cycles by TGA and batch fluidized bed reactor. Both showed high solids conversion by TG under the tested conditions; appropriated resistance to fracture; rate indexes relatively high although $\mathrm{Mn}-\mathrm{ZrM}$ showed agglomeration and deactivation during batch fluidized bed tests. 
Reactivity of the Mn-ZrSG oxygen carrier with methane increases with temperature operating with $\mathrm{CH}_{4}$ although suffered from significant deactivation. This was different to the results found during multiple redox cycles by TGA. There was not a clear reason for this decrease in the reactivity that likely could be due to the uncomplete oxidation in the batch fluidized bed reactor, although further investigations are needed. On the other hand, it presented high and constant reactivity with $\mathrm{CO}$ and $\mathrm{H}_{2}$ in all the range of temperatures tested, being suitable for iG-CLC processes of coal or biomass and syngas combustion. Agglomeration problems were not found and the attrition losses were small. Calculated lifetime was around 11000 hours, much higher than any other Mn based material developed or tested.

\section{Acknowledgements}

This work was partially supported by the Spanish Ministry of Economy and Competitiveness via ENE2014-56857-R and ENE2016-77982-R, by the European Regional Development Fund (ERDF). The authors thanks to CNPq for the funding received by the Project 405792/2013-1 and T. Costa thanks to CNPq for the grant SWE 200354/2014-0. 


\section{References}

1. Lyon RK, Cole JA. Unmixed combustion: an alternative to fire. Comb Flame 2000;121:249-61.

2. Lyngfelt A, Leckner B, Mattisson T. A fluidized bed combustion process with inherent $\mathrm{CO}_{2}$ separation, aplication to Chemical Looping Combustion. Chem Eng Sci 2001;56:3101-13.

3. Hossain, $\mathrm{MM}$, de Lasa $\mathrm{HI}$. Chemical-looping combustion $(\mathrm{CLC})$ for inherent $\mathrm{CO}_{2}$ separations-a review. Chem Eng Sci 2008;63:4433-51.

4. Lyngfelt A, Johansson M, Mattisson T Chemical-Looping Combustion - Status of development. Proc $9^{\text {th }}$ Int Conf on circulating fluidized beds (CFB9), Hamburg, Germany (2008).

5. Fan L-S. Chemical Looping Systems for Fossil Energy Conversions, Hoboken, New Jersey, John Willey \& Sons, Inc. 2010.

6. Adánez J, Abad A, García-Labiano F, Gayán P, de Diego LF. Progress in Chemical-Looping Combustion and Reforming Technologies. Prog Energy Combust Sci 2012;38:215-82.

7. Adánez J, Abad A, Mendiara T, Gayán P, de Diego LF, García-Labiano F. Chemical looping combustion of solid fuels. Prog Energy Combust Sci 2018;65: 6-66.

8. Johansson M, Mattisson T, Lyngfelt A. Comparison of oxygen carriers for chemical-looping combustion. Thermal Science 2006;10:93-107.

9. Abad A, Mattisson T, Lyngfelt A, Rydén M. Chemical-Looping Combustion in a 300 W continuously operating reactor system using a manganese-based oxygen carrier. Fuel 2006;85:1174-85.

10. Jerndal E, Mattisson T, Lyngfelt A. Thermal analysis of chemical-looping combustion. Chem Eng Res Des 2006;84:795-806.

11. Stobbe ER, de Boer BA, Geus JW. The reduction and oxidation behaviour of manganese oxides. Catalysis Today 1999;47:161-7.

12. Zafar Q, Abad A, Mattisson T, Gevert B, Strand M. Reduction and oxidation kinetics of $\mathrm{Mn}_{3} \mathrm{O}_{4} / \mathrm{Mg}-\mathrm{ZrO}_{2}$ oxygen carrier particles for chemical-looping combustion. Chem Eng Sci 2007;62:6556-67.

13. Tang $M, X u L$, Fan $M$. Progress in oxygen carrier development of methane-based chemical-looping reforming: A review. Applied Energy 2015;151:143-56.

14. Mattisson T, Järdnäs A, Lyngfelt A. Reactivity of Some Metal Oxides Supported on Alumina with Alternating Methane and Oxygen-Application for Chemical-Looping Combustion. Energy Fuel 2003;17:643-51. 
15. Adánez J, de Diego LF, García-Labiano F, Gayán P, Abad A. Selection of oxygen carriers for chemical-looping combustion. Energy Fuels 2004;18:371-7.

16. Cho P, Mattisson T, Lyngfelt A. Comparision of iron-, nickel,copper-, and manganese-based oxygen carriers for chemical-looping combustion. Fuel 2004;83:1215-25.

17. Zafar Q, Mattisson T, Gevert B. Redox Investigation of Some Oxides of Transition-State Metals $\mathrm{Ni}, \mathrm{Cu}, \mathrm{Fe}$, and $\mathrm{Mn}$ Supported on $\mathrm{SiO}_{2}$ and $\mathrm{MgAl}_{2} \mathrm{O}_{4}$. Energy Fuels 2006;20:34-44.

18. Forutan HR, Karimi E, Hafizi A, Rahimpour MR, Keshavarz P. Expert representation chemical looping reforming: A comparative study of $\mathrm{Fe}, \mathrm{Mn}$, $\mathrm{Co}$ e $\mathrm{Cu}$ as oxygen carriers supported on $\mathrm{Al}_{2} \mathrm{O}_{3}$. J Ind Eng Chem 2015;21:900-11.

19. Mattisson T, Lyngfelt A. Applications of chemical-looping combustion with capture of $\mathrm{CO}_{2}$. In: Second Nordic Minisymposium on $\mathrm{CO}_{2}$ capture and storage, Goterg, Sweeden; 2001.

20. Rydén M, Lyngfelt A, Mattisson T, de Chen, Holmen A, Bjorgum E. Novel oxygen-carrier materials for chemical-looping combustion and chemical-looping reforming; $\mathrm{La}_{\mathrm{x}} \mathrm{Sr}_{1-\mathrm{x}} \mathrm{Fe}_{\mathrm{y}} \mathrm{Co}_{1-\mathrm{y}} \mathrm{O}_{3-\delta}$ perovskites and mixedmetal oxides of $\mathrm{NiO}, \mathrm{Fe}_{2} \mathrm{O}_{3}$ and $\mathrm{Mn}_{3} \mathrm{O}_{4}$. Int J Greenhouse Gas Control 2008;2:21-36.

21. Cho P, Mattisson T, Lyngfelt A. Defluidization Conditions for a Fluidized Bed of Iron Oxide-, Nickel Oxide-, and Manganese Oxide-Containing Oxygen Carriers for Chemical-Looping Combustion. Ind Eng Chem Res 2006;45:968-77.

22. Mei D, Mendiara T, Abad A, de Diego LF, García-Labiano F, Gayán P, Adánez J, Zhao H. Manganese minerals as oxygen carriers for chemical looping combustion of coal. Ind Eng Chem Res 2016;55:6539-46.

23. Velasco-Sarria F, Forero CR, Adanez-Rubio I, Abad A, Adanez J. Assessment of low-cost oxygen carrier in South-western Colombia, and its use in the in-situ gasification chemical looping combustion technology. Fuel 2018;218:417-426.

24. Fossdal A, Bakken E, Øye BA, Schøning C, Kaus I, Mokkelbost T, Larring Y. Study of inexpensive oxygen carriers for chemical looping combustion. Int J Greenhouse Gas Control 2011;5:483-8.

25. Mei D, Mendiara T, Abad A, de Diego LF, García-Labiano F, Gayán P, Adánez J, Zhao H. Evaluation of Manganese Minerals for Chemical Looping Combustion. Energy Fuels 2015;29:6605-15.

26. Linderholm C, Schmitz M, Biermann N, Hanning M, Lynfelt A. Chemical looping combustion of solid fuels in 100 kW unit using sintered manganese ore as oxygen carrier. Int J Greenhouse Gas Control 2017;65:170-81. 
27. Schmitz M, Linderholm C, Hallberg P, Sundqvist S, Lyngfelt A. Chemical looping combustion of solid fuels using manganese ores as oxygen carriers. Energy Fuels 2016;30:1204-16.

28. Larring $\mathrm{Y}$, Pishahang $\mathrm{M}$, Sunding $\mathrm{MF}$, Tsakalakis $\mathrm{K}$. Fe-Mn based minerals with remarkable redox characteristics for chemical looping combustion. Fuel 2015;159:169-78.

29. Azimi G, Leion H, Ryden M, Mattisson T, Lyngfelt A. Investigation of different Mn-Fe oxides as oxygen carriers for Chemical Looping Combustion with Oxygen Uncoupling (CLOU). Energy Fuels 2013;27:367-77.

30. Lambert A, Delquié C, Clemencon I,Comte E, Lefevre V, Rijousseau J et al. Synthesis and characterization of bimetallic Fe-Mn oxides for chemical looping cimbustion. Energy Procedia 2000;1:375-81.

31. Pérez-Vega R, Abad A, Gayán P, de Diego LF, García-Labiano F, Adánez J. Development of $\mathrm{Mn}_{0.77} \mathrm{Fe}_{0.23} \mathrm{O}_{3}$ particles as an oxygen carrier for coal combustion with $\mathrm{CO}_{2}$ capture via in-situ gasification chemical looping combustion (iG-CLC) aided by oxygen uncoupling (CLOU). Fuel Process Technol 2017;164:69-79.

32. Pérez-Vega R, Abad A, García-Labiano F, Gayán P, de Diego LF, Izquierdo T, Adánez J. Chemical looping combustion of gaseous and solid fuels with manganese-iron mixed oxides as oxygen carriers. Energy Convers Managmnt 2018;159:221-31.

33. Rydén M, Lyngfelt A, Mattisson T. Combined Mn/iron oxides as oxygen carrier for chemical looping combustion with oxygen uncoupling (CLOU) in a circulating fluidized reactor system. Energy Procedia 2011;4:341-8.

34. Rydén $M$, Kallen $M$, Jing $D$, Hedayati AS, Mattisson T, Lyngfelt $A$. $\left.F e_{1-x} M n_{x}\right) T i y O_{3}$ based oxygen carrier for chemical looping combustion and chemical-looping with oxygen uncoupling. Energy Procedia 2014;51:8598.

35. Gayán P, Cabello A, García-Labiano F, Abad A, de Diego LF, Adánez J. Performance of a low Ni content oxygen carrier for fuel gas combustion in a continuous CLC unit using a $\mathrm{CaO} / \mathrm{Al}_{2} \mathrm{O}_{4}$ system as support". Int J Greenhouse Gas Control 2013;14:209-19.

36. Costa TR, Gayán P, Abad A, García-Labiano F, de Diego LF, Melo DMA, Adánez J. Promising impregnated Mnbased oxygen carrier for chemical Looping Combustion of gaseous fuels. Energy Procedia 2017;114:325-33.

37. Dueso C, García-Labiano F, Adánez J, de Diego LF, Gayán P, Abad A. Syngas combustion in a chemical looping system using an impregnated Ni-based oxygen carrier. Fuel 2009;88:2357-64.

38. Toussaint $\mathrm{H}$. Étude sur les réactions dans l'état solide entre le byoxyde $\mathrm{MnO}_{2}$ ou le sesquioxyde $\mathrm{Mn}_{2} \mathrm{O}_{3}$ et les oxydes CaO, ZrO, MgO ou CdO. Revue de Chimie Minérale 1964;1:141198. 
39. Valverde-Díez N, Grande-Fernández D. Termary compounds of the System Mg-Mn-O as oxygen sensors. Solid State Ionics, North-Holland, Amsterdam, 1988;28-30,1697-700.

40. Mariscal R, Soria J, Peña MA, Fierro LG. Features of Li-Mn-MgO catalysts and Their Relevance in the Oxidative Coupling Metane. Journal of Catalysis 1994;147:535-43.

41. Bulavchenko OA, Afonasenko TN, Tsyrul'nikov PG, Tsybulya SV. Effect of heat treatment conditions on the structure and catalytic properties of $\mathrm{MnO}_{x} / \mathrm{Al}_{2} \mathrm{O}_{3}$ in the reaction of $\mathrm{CO}$ oxidation. Applied Catalysis $\mathrm{A}$ : General 2013;459:73-80.

42. de Frang, Xie J, Hu H, Yang H, He F, Fu Z. Identification of $\mathrm{MnO}_{\mathrm{x}}$ species and $\mathrm{Mn}$ Valence states in $\mathrm{MnO}_{\mathrm{x}} / \mathrm{TiO}_{2}$ catalysts for low temperature SCR. Chem Eng Journal 2015;271:23-30.

43. Cabello A, Gayán P, García-Labiano LF, Abad A, Adánez J. On the attrition evaluation of oxygen carriers in Chemical Looping Combustion. Fuel Proc Techonol 2016;148: 188-97.

44. Leion $\mathrm{H}$, Larring $\mathrm{Y}$, Bakken $\mathrm{E}$, Bredesen R, Mattisson $\mathrm{T}$, Lyngfelt A. Use of $\mathrm{CaMn}_{0.875} \mathrm{Ti}_{0.125} \mathrm{O}_{3-\delta}$ as Oxygen Carrier in Chemical-Looping With Oxygen Uncoupling. Energy Fuels 2009;23:5276-83. 